\title{
Physical Properties of Electrodeposited Chromium
}

\author{
By Abner Brenner, Polly Burkhead, and Charles Jennings
}

\begin{abstract}
The following properties of chromium, deposited under a wide variety of plating conditions, have been measured; density, hardness, tensile strength, Young's modulus of elasticity, ductility, electrical resistivity, and stress in the deposit. The oxygen and hydrogen content were determined. The effect of heat treatments up to $1,200^{\circ} \mathrm{C}$ on certain of these properties has been determined, and some work has been done on the properties of chromium-iron alloys deposited from modified chromic acid solutions. A relation between the hydrogen and oxygen content of the deposits has been shown to exist, and the effect of the oxygen content on the physical properties has been studied.
\end{abstract}

\section{Introduction}

One of the advantages of electrodeposited metals is the possibility of producing deposits of a given metal with widely different properties by varying the conditions of deposition. This feature is even more important in engineering applications of electrodeposits than for their ornamental use. The increased use of plated metal coatings and of electroformed articles during the war led to a demand for a more exact knowledge of the physical properties of deposited metals, as a guide in the selection of metals to meet specified types of service.

The original impetus for this study came from an attempt to electrodeposit either chromium or one of its alloys in a form that would have some ductility. Although this aim was not achieved, this work led to the study and measurement of these properties of chromium on which little data were available.

The great hardness of electrodeposited chromium has been of considerable practical and theoretical interest, and consequently most study has been devoted to this property in the past. Few broad investigations of the other properties of chromium deposits have been made, and the trend has been to study minutely a few types of deposits with respect to a given property. In this investigation no exhaustive study of any single physical property was made, but several properties of deposits, which were produced under widely different conditions, were determined in order to correlate the physical properties and the conditions of depositions; and to establish the range of each property. Reference to table 11 will give an idea of the great range attainable in the properties of chromium deposits.

In this study the following measurements were made on the deposits: Oxygen and hydrogen content, hardness, density, tensile strength, Young's modulus, ductility, and electrical resistivity. The effect of heat treatment up to $1,200^{\circ}$ $\mathrm{C}$ on some of these properties was determined. In addition, observations were made on the cathode current efficiency and on the stress in the deposits as plated. Certain factors, such as the crystal structure, were not investigated, because that subject has been adequately treated by others. ${ }^{1}$ No previous data on either the tensile strength or Young's modulus were found in the literature.

One result of this study has shown that deposits obtained at $85^{\circ} \mathrm{C}$ and above are much sounder than the bright deposits at about $50^{\circ} \mathrm{C}$.

\section{Plating Solutions and Conditions of Deposition}

The specimens employed in these studies were deposited from solutions, containing chromic acid in concentrations from 50 to $500 \mathrm{~g} /$ liter together with either (a) sulfate with a weight ratio of

\footnotetext{
1 After this paper was written, a paper was received from Cloyd A. Snavely on the theory of chromium plating. He discusses the mechanism of chromium plating on the basis of X-ray data and attributes the differences in properties of chromium to the formation of hydrides.
} 
TABLE 1. Conditions used in chromium deposition

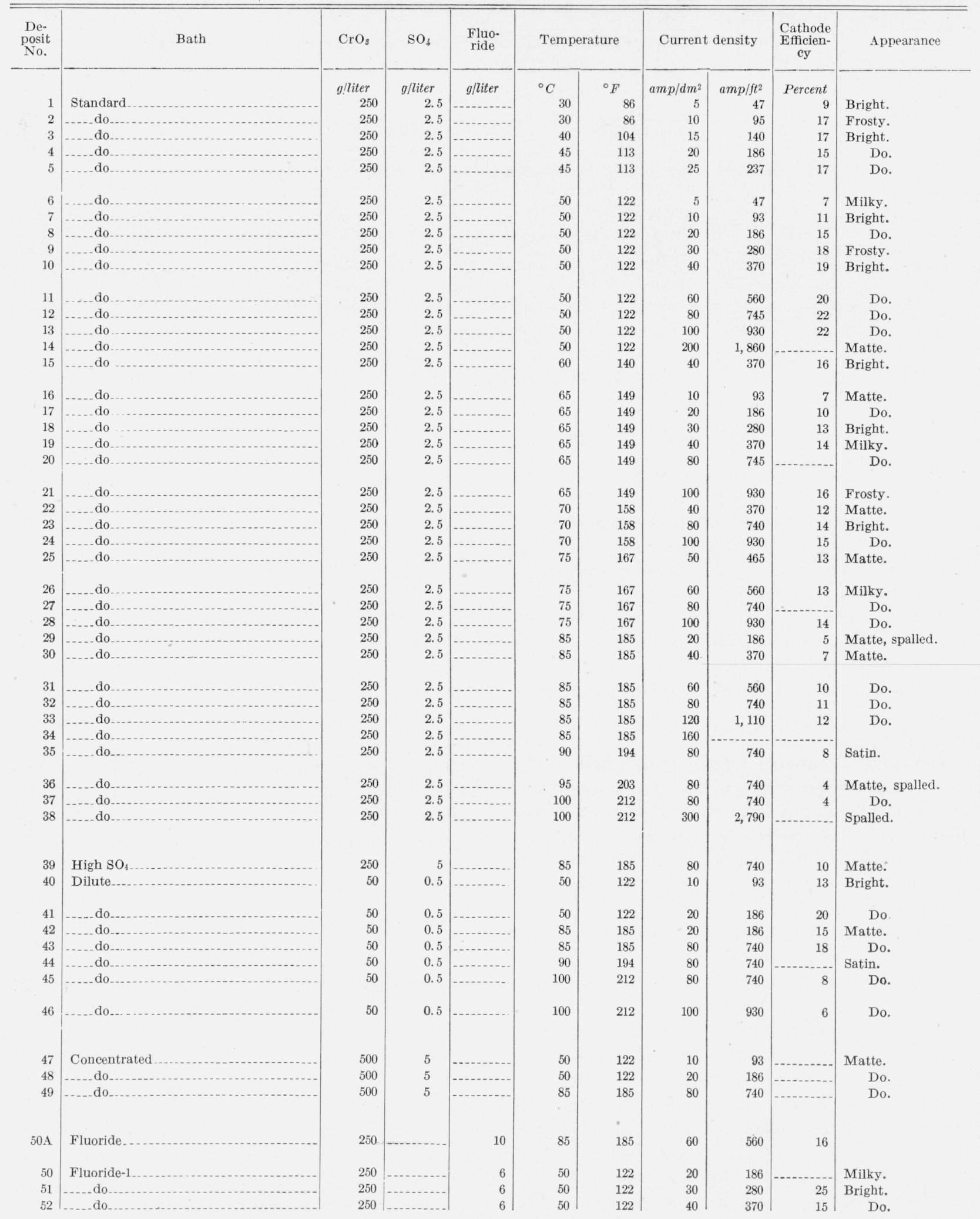


TABLE 1. Conditions used in chromium deposition-Continued

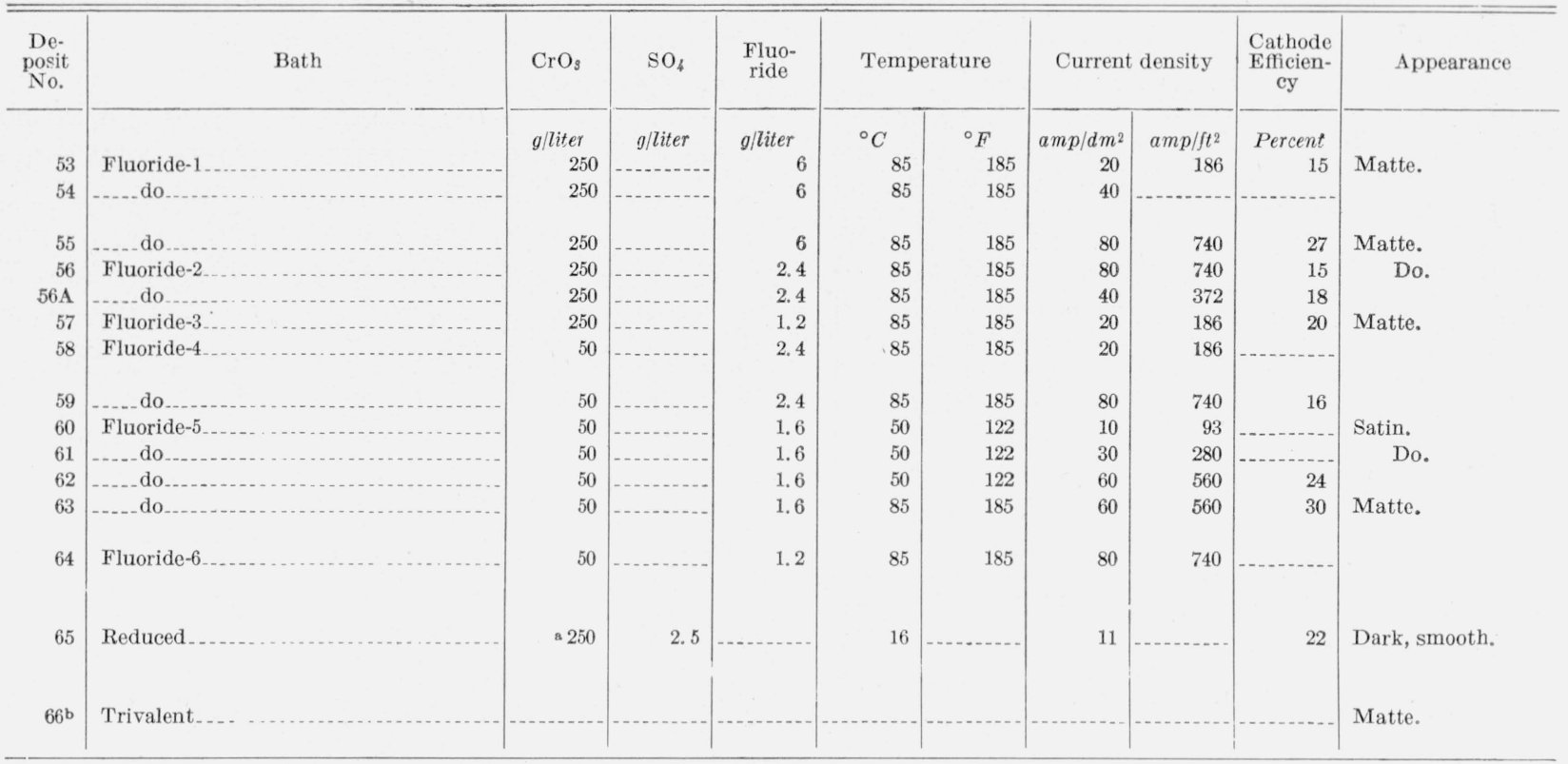

s Solution and plating conditions according to Wright, Hirst, and Riley [39]. A solution containing $\mathrm{CrO}_{3}, 250 \mathrm{~g} / \mathrm{liter}$, was reduced with oxalic acid to contain 25 percent of the chromium in the trivalent condition.

b Specimen of chromium received from the U. S. Bureau of Mines. Deposited from a trivalent solution [22].

$\mathrm{CrO}_{3} / \mathrm{SO}_{4}$ from 50 to 100 ; or (b) fluoride with a weight ratio of $\mathrm{CrO}_{3} / \mathrm{F}$ of from 20 to 200 . The range of plating conditions was as follows: Temperature, from $16^{\circ}$ to $100^{\circ} \mathrm{C}$; current density, from 5 to $300 \mathrm{amp} / \mathrm{dm}^{2}$. The principal baths and conditions of operation are listed in table 1.

The baths were made from a pure grade of commercial $\mathrm{CrO}_{3}$, the sulfate content of which was determined. Required additions of sulfate were added as sulfuric acid. The sulfate content was checked by analysis and the $\mathrm{CrO}_{3}$ content with a hydrometer. Fluoride was added as hydrofluoric acid of a known strength, or as potassium fluoride. Some exploratory studies were made on trivalent chromium baths of the type developed by the United States Bureau of Mines [22]* for the electrowinning of chromium, and a few analyses and measurements were made on samples received from the Bureau of Mines.

The baths were contained in 6-liter glass cylinders. The anode was a cylinder of chemical lead, which lined the inside of the container. The cathode tube was supported vertically in the center of the jar. The desired temperature was thermostatically controlled to $\pm 1^{\circ} \mathrm{C}$, and the

\footnotetext{
${ }^{*}$ Figures in brackets indicate the literature references at the end of this paper.
}

solution level was maintained constant. The current density was controlled to \pm 5 percent. The solutions containing fluorides were also contained in glass vessels, as it was found that for the concentrations employed no appreciable attack of the glass occurred. Because both lead and graphite anodes were rapidly attacked in baths containing fluoride, platinum anodes were used.

The cathode efficiencies reported in table 1 were determined by depositing chromium on gold rods under the same conditions as were used for deposition of test specimens. The literature [9] contains data on the cathode current efficiencies of chromium plating solutions for temperatures up to $65^{\circ} \mathrm{C}$. However, the data for solutions operated at $85^{\circ} \mathrm{C}$ are not very extensive. For this reason data are given in figure 1 for solutions operated at $85^{\circ} \mathrm{C}$ and containing either sulfate or fluoride. The current efficiency of the dilute sulfate solution, containing $\mathrm{CrO}_{3}, 50 \mathrm{~g}$ /liter and $\mathrm{SO}_{4}, 0.5$ $\mathrm{g} /$ liter, is about double that of the standard solution. The curves for the fluoride solutions are unusual in that they show maxima at a moderate current density. The maxima occur only for a limited range of fluoride concentration (from 0.8 to $2.0 \mathrm{~g} /$ /iter). Outside of this range the curves resemble those for the sulfate solutions, which 


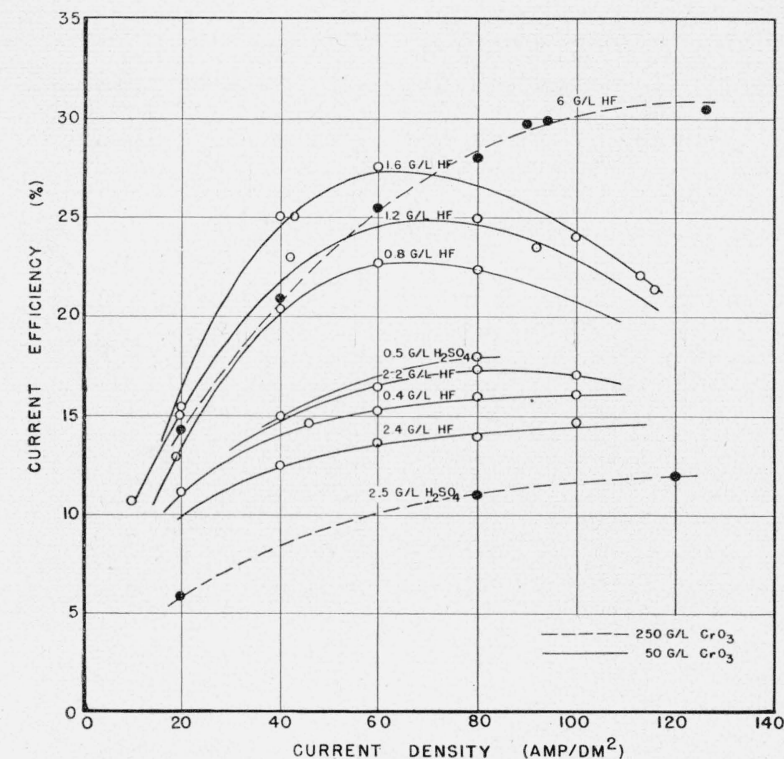

Figure 1. Effect of current density on the cathode efficiencies of chromium deposition at $85^{\circ} \mathrm{C}$.

Standard, - dilute, $\bigcirc$.

normally show a continuous increase of current efficiency with current density. Wick [36] however, reports that at $85^{\circ} \mathrm{C}$ a maximum efficiency is also found for sulfate solutions at a very high current density. (It may be noted that a strike was necessary to obtain initial plating from certain of the flouride solutions when a low current density was used.)

\section{Deposition of Specimens}

For most of the measurements, the chromium was deposited on a copper tube, which was then dissolved out to leave a tube of chromium. The use of a tube has some advantages over a flat specimen: (1) A more uniform current density can be obtained on a tube, (2) the tubular specimen does not distort, when the base metal is dissolved away, because the stresses are evenly distributed, whereas a thin, flat deposit might curl or warp, (3) a thin walled tube can be handled more safely than a flat specimen, because it has a shorter length of edge. Thin sheets of chromium are quite fragile.

The copper tube used as a base for the chromium deposit had an outside diameter of about $5 \mathrm{~mm}$ $(3 / 16 \mathrm{in}$.) and a wall thickness of $0.25 \mathrm{~mm}(0.01 \mathrm{in}$.). The outside of the copper tube was buffed to a bright smooth finish with Vienna lime. A suitable length, e.g. 20 to $40 \mathrm{~cm}$ ( 8 to $16 \mathrm{in}$.) was flattened at each end and sealed. Stop-off lacquer was applied to the lower end for a distance of about 1 $\mathrm{cm}$ and to the top for a distance of about $1 \mathrm{~cm}$ both above and below the solution level.

The deposits of chromium varied in thickness from 0.05 to $0.25 \mathrm{~mm}$ ( 0.002 to $0.01 \mathrm{in}$.), depending on the properties to be measured. As the current density was slightly higher at each end of the tube than over the remainder of the surface, about $1 \mathrm{~cm}$ of the deposit from each end was discarded in preparing the specimens for test. The copper was dissolved from the inside of each tube by immersion in dilute nitric acid, or in a solution containing $\mathrm{CrO}_{3}, 500 \mathrm{~g} /$ liter and sulfuric acid, 50 $\mathrm{g}$ /liter.

Spectrochemical analyses showed that the chromium deposits contained no more than a few hundredths of a percent of foreign metals.

\section{Appearance and Structure of Chro- mium Deposits}

Inasmuch as the surface appearance and microstructure of chromium have been extensively studied by previous investigators, and numerous photomicrographs are in the literature, no specific work on this phase of the subject was attempted, and our observations on the structure were incidental. However, a summary of the available information on the structure of chromium is given here as a basis for discussions of its relation to other properties.

\section{Macrostructure}

It is difficult to define the appearance of the deposits in words. The terms used in table 1 have the following meanings: A bright deposit is one that is both bright and smooth; a milky deposit is semibright and smooth; a frosty deposit appears bright but slightly rough or coarse; a satin deposit is semibright and rough; a matte deposit is dull and rough; a spalled deposit is one from which, on standing, small particles are spontaneously detached, often audibly (fig. 2).

Bright chromium deposits have been of the most commercial value. The conditions for their production cannot be closely defined, because they involve both temperature and current density. It is customary to specify the conditions in terms of "a bright plating range" that shows the limits 

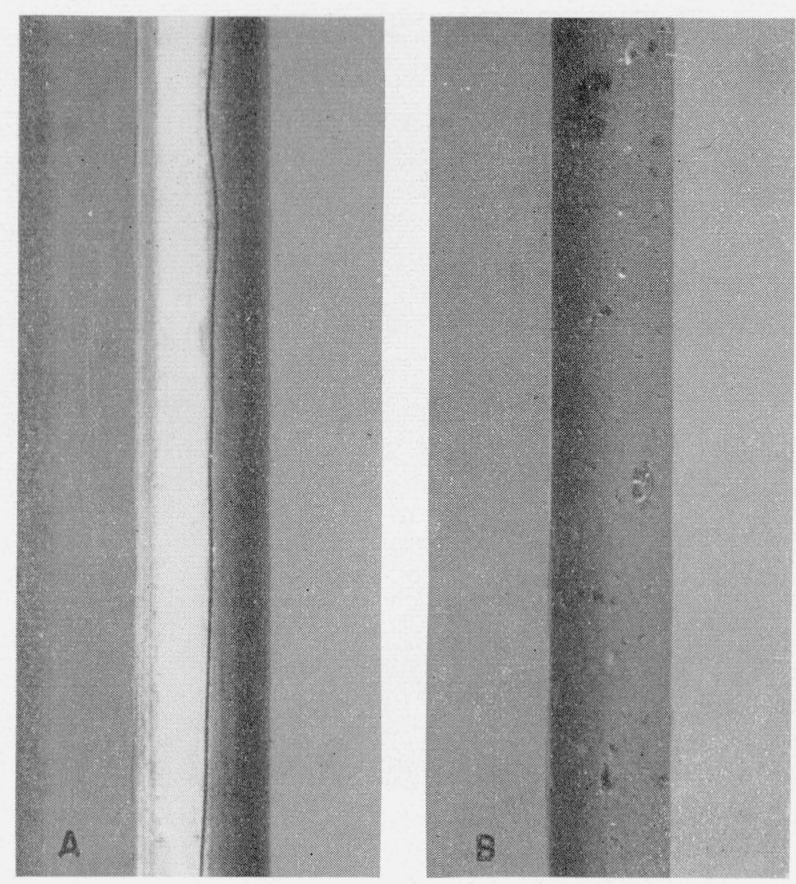

Figure 2. A, Chromium deposit, showing crack formed after dissolving away the copper tube upon which it had been plated; deposit obtained from the standard bath at $85^{\circ} \mathrm{C}$ and $80 \mathrm{amp} / \mathrm{dm}^{2}$. B. spalled deposit obtained from a standard bath at $100^{\circ} \mathrm{C}$ and $80 \mathrm{amp} / \mathrm{dm}^{2}$.

of current density and temperature. In the standard chromium plating solution, containing $\mathrm{CrO}_{3}, 250 \mathrm{~g} /$ liter, and sulfate $2.5 \mathrm{~g} /$ liter, bright deposits are usually obtained at cathode efficiencies between 8 and 16 percent. At temperatures above $75^{\circ} \mathrm{C}$, it is doubtful if bright deposits can be obtained, even at high current densities. Milky deposits are obtained at cathode efficiencies below 8 percent, and frosty or matte deposits above 16 percent. The data in table 1 show that, if the observations are not restricted to the standard solution, there is no close correlation between the appearance of the deposits and the conditions of deposition.

Bright chromium contains a network of hairline cracks and/or inclusions that are visible with low magnification or occasionally even to the unaided eye (fig. 3). As the temperature of deposition is raised above $55^{\circ} \mathrm{C}$, the deposits contain fewer cracks, and the matte deposits obtained at higher temperature may be entirely free from cracks (fig. 4). Some of the matte deposits, however, occasionally develop a few very large coarse cracks when the base metal is stripped from them (fig. 2). The deposits obtained at the higher temperatures

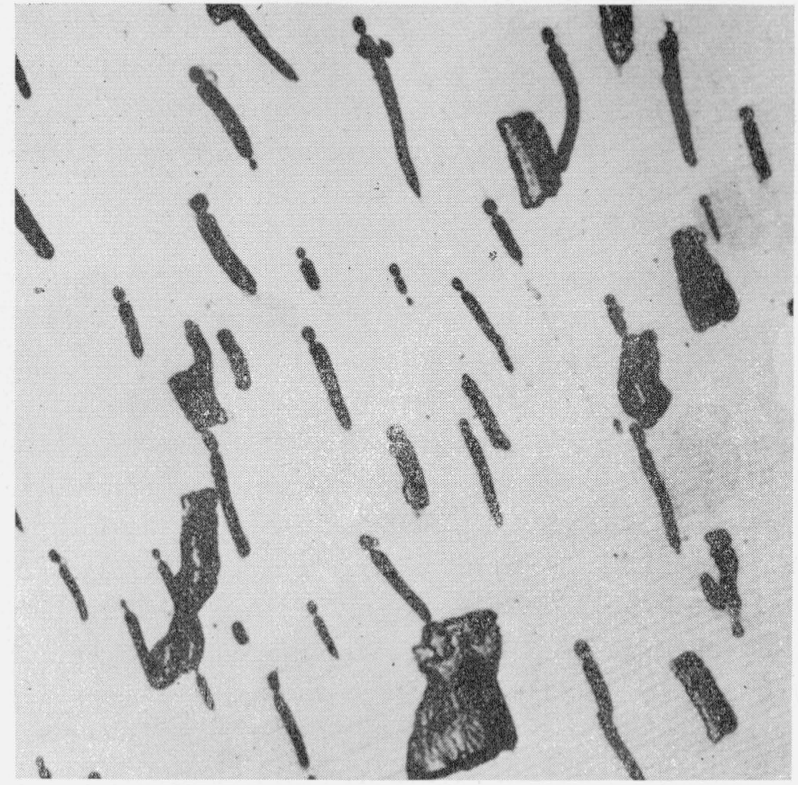

F1GURE 3. Inclusions in bright chromium, deposited at $50^{\circ} \mathrm{C}$, and $20 \mathrm{amp} / \mathrm{dm}^{2}$ from a standard bath, $\times 500$.

Etched with hydrochloric acid.

afford better protection to steel in salt spray tests than the bright deposits because of the absence of cracks.

The spalled deposits described above (see fig. 2) do not appear to have been mentioned in the literature previously. They are produced at relatively low current densities and at temperatures of $85^{\circ} \mathrm{C}$ or above, under which conditions the current efficiencies are less than 6 percent. (Table 1; deposits 29, 36, 37, 38).

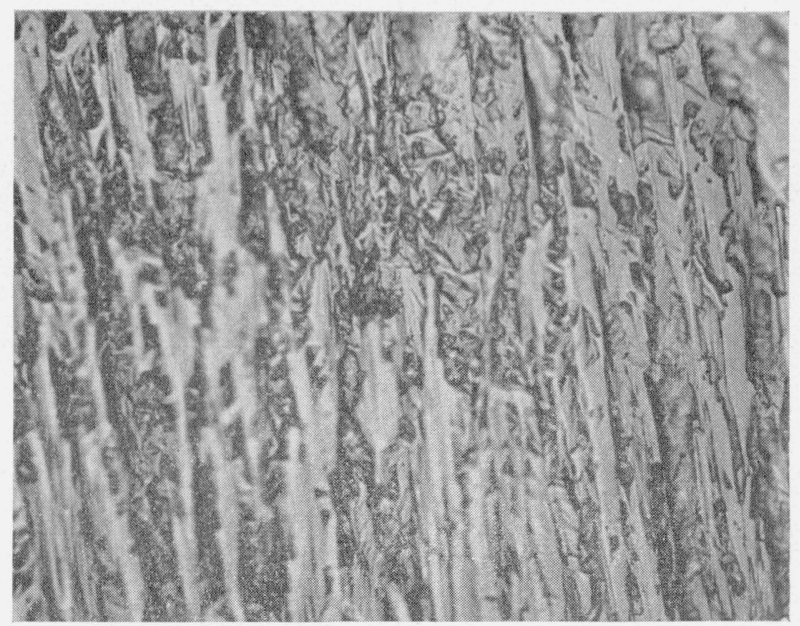

Figure 4. Structure of chromium, deposited from the dilute bath at $100^{\circ} \mathrm{C}$ and $80 \mathrm{amp} / \mathrm{dm}^{2}, \times 500$.

Etched with hydrochloric acid. 


\section{Microstructure}

Chromium deposits are very fine grained. On the basis of X-ray data, the bright deposits have been estimated to have grains as small as $10^{-7} \mathrm{~cm}$ in diameter. It is generally held that the grain size of chromium is too small to be resolved under the microscope. Cymboliste [7] showed photomicrographs that he believed to show the presence of grains. The authors do not concur with his interpretation. In common with others, the authors have been unable to detect microscopically any grain structure in chromium as deposited, but have obtained well defined grains in chromium annealed in vacuum at $1,400^{\circ} \mathrm{C}$. (fig 5). A similar result was obtained by Adcock [2]. In this photomicrograph, it will be noticed that the inclusions shown in figure 3 have coalesced into granular particles (probably of $\mathrm{Cr}_{2} \mathrm{O}_{3}$ ) situated mainly at the grain boundaries. In a preliminary examination of a chromium deposit with the electron microscope, at a magnification of 50,000, a photomicrograph was obtained showing light and dark areas, the meaning of which was not interpreted. Figure 6 shows the result obtained by transmitting the electron beam through a film of chromium about one-millionth inch $(0.000025$ $\mathrm{mm}$ ) thick.

Ordinary electrodeposited chromium has a body-centered cubic cell. Several different investigators have measured the lattice parameter and obtained closely agreeing values of about

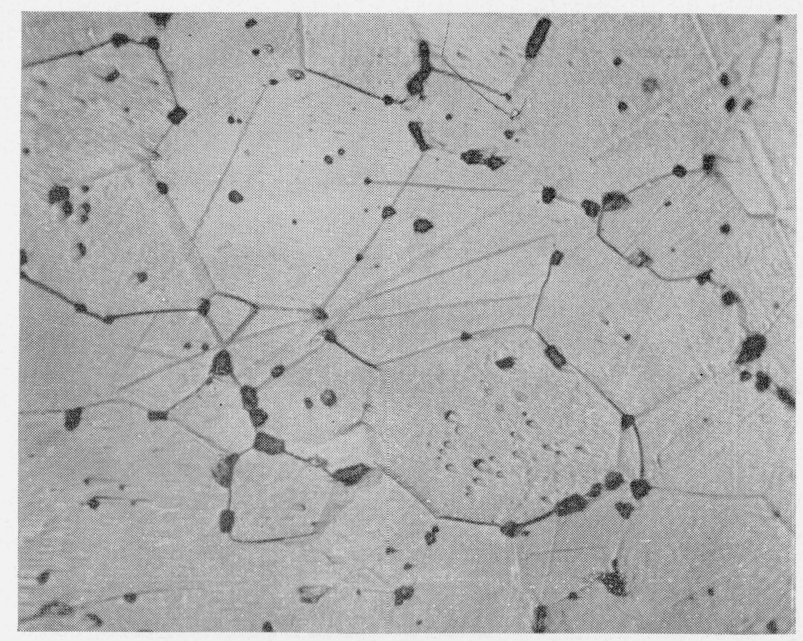

Figure 5. Grain structure in the deposit of figure 2, after annealing at $1,400^{\circ} \mathrm{C}, \times 500$.

Etched with hydrochloric acid. Note particles of chromic oxide at grain boundaries.

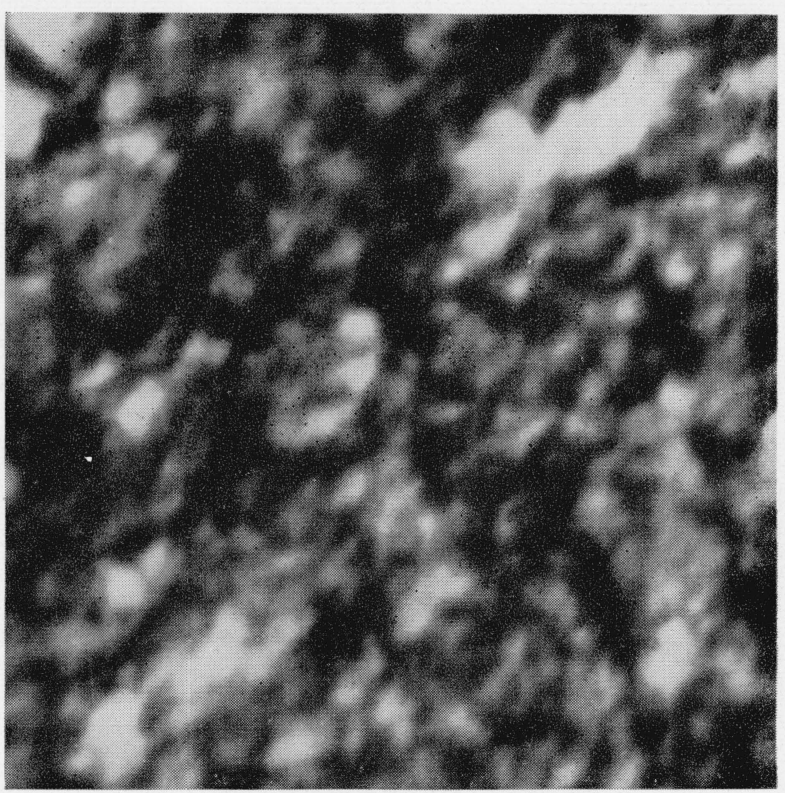

Figure 6. Photomicrograph by the electromicroscope, $\times 50,000$.

Electron beam transmitted through a film of bright chromium one millionth of an inch thick.

2.878 A. Under certain conditions of deposition, chromium can be obtained as a hexagonal close-packed modification [31]. Wood [38] has shown that the lattice of electrodeposited chromium is 0.3 percent larger than that of annealed chromium. The interpretation of this expansion is not clear, as it may result from strains in the lattice or from the presence of dissolved hydrogen or oxygen. The bright deposits have a preferred crystal orientation so that one set of the 111 planes are parallel to the plane of the deposits $[3,40]$. The condition of dull deposits may range from partially oriented to completely random. Hume-Rothery [40] correlated the crystal orientation of the deposits with their brightness, hardness, and stress, but did not discuss the reason for the relationships. We do not believe that crystal orientation is primarily responsible for the hardness or stress in deposited metals, but that it is merely an attendant circumstance. The oxide content of deposits, which Hume-Rothery does not discuss, has a far greater influence on physical properties than crystal orientation.

\section{Hydrogen and Oxygen Content of Chromium Deposits}

Electrodeposited chromium contains appreciable amounts of hydrogen and oxygen. The 
earlier investigators were interested in determining the amount of hydrogen in chromium because of the theory, once prevalent, that the hardness was caused by hydrogen. They did very little work on the determination of the oxygen content of the deposits, although at the present time this impurity is considered to have a larger effect on the physical properties of electrodeposits.

\section{Methods of Determining Hydrogen and Oxygen}

Previous investigators determined the hydrogen in chromium by heating the deposit to different temperatures in a vacuum and noting the increase in pressure. Adcock [2] determined the oxide content of chromium by heating it to $800^{\circ} \mathrm{C}$ in a vacuum, and then dissolving the metal in hydrochloric acid. A residue of $\mathrm{Cr}_{2} \mathrm{O}_{3}$ was left that contained the oxygen originally present in the sample. Prior to the heat treatment the chromium dissolved completely in acid.

Most of the data given in table 2 on the hydrogen and oxygen content of chromium were obtained by the vacuum-fusion method, which has the advantage that the determination of both hydrogen and oxygen can be made on a single sample. For these measurements the authors are indebted to H. E. Cleaves of the Metallurgy Division of this Bureau. Some oxide determinations were made also by Adcock's method, and the results were found to agree well with those of the vacuumfusion method.

The vacuum-fusion method [33] consists in heating a sample of chromium, about $0.5 \mathrm{~g}$, in molten iron at $1,600^{\circ} \mathrm{C}$. The iron is contained in a graphite crucible and, hence, is saturated with carbon. The apparatus is highly evacuated. The hydrogen is given off uncombined and the oxygen as carbon monoxide. The quantity of these gases is determined by noting the decrease in the pressure of the system when they are consecutively removed through oxidation and absorption. This method is not suitable for measuring the amount of hydrogen existing in a deposit immediately after it is withdrawn from the bath, because about 3 hours of pumping at room temperature is required to get the system outgassed before the analysis begins, and during this time some hydrogen may escape from the specimen. - There is evidence, however, to show that chromium does not rapidly lose its hydrogen at room temperature, and that there is no necessity for im-
TABLE 2. Hydrogen and oxygen content of electrodeposited chromium

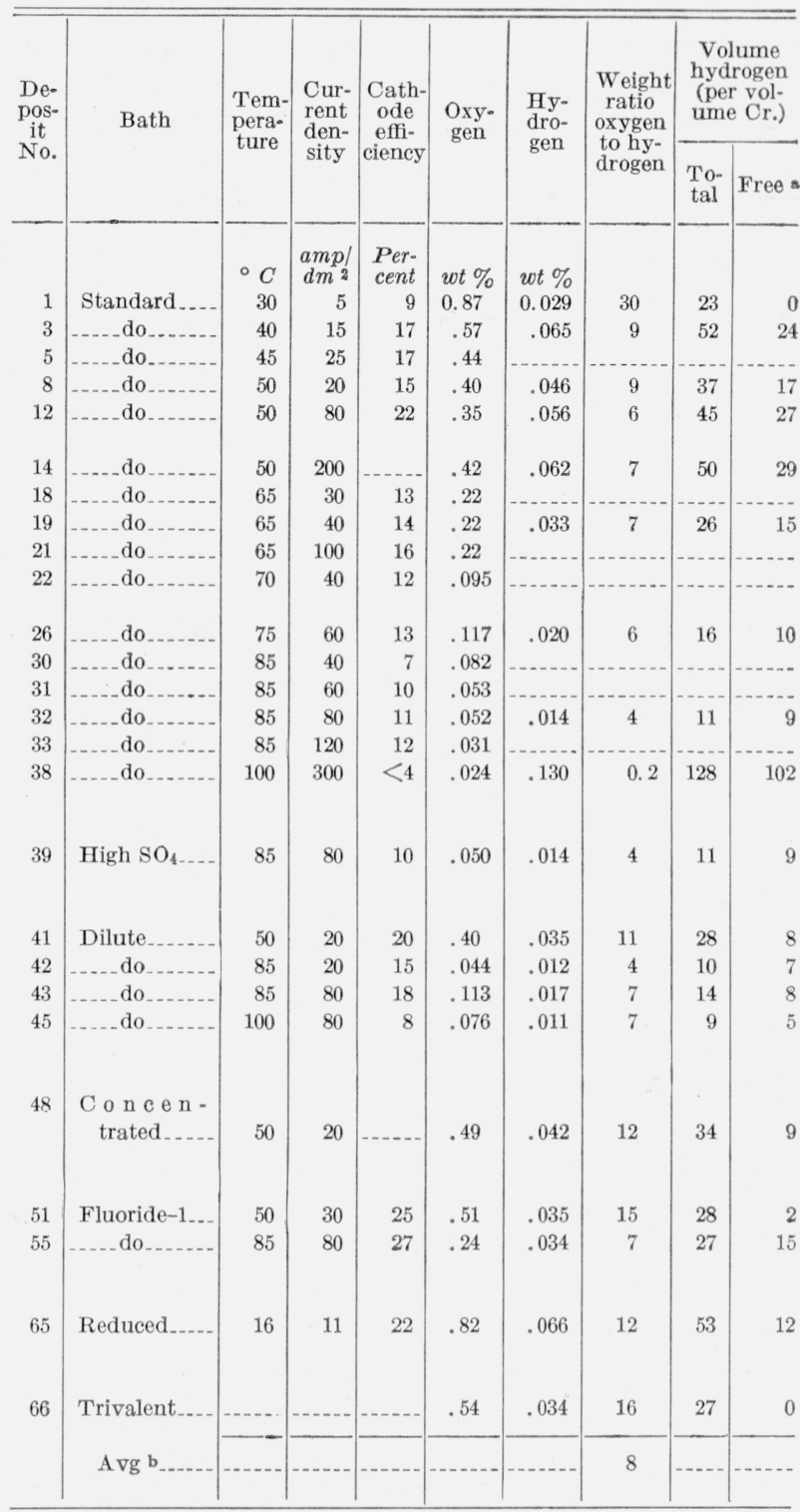

a Calculated on basis of oxygen combining with hydrogen in weight ratio of 16 , i. e., as $\mathrm{OH}$.

b Experiments 1 and 38 excluded from average.

mediate analysis of the sample. Makariewa and Birühoff [26] found that a specimen of chromium that had stood $1 \frac{1}{2}$ years had virtually the same content of hydrogen as one that was analyzed immediately. The data in table 3 show that specimens $B$ and $C$, which were analyzed immediately after deposition, had about the same hydrogen content as specimens $D$ and $E$, which had been allowed to age a few months. 
TABLE 3.-Effects of standing or heating upon the oxygen and hydrogen content of electrodeposited chromium

[All deposits produced in the standard bath at $50^{\circ} \mathrm{C}$ and $20 \mathrm{amp} / \mathrm{dm}^{2}$ ]

\begin{tabular}{|c|c|c|c|c|}
\hline \multirow{2}{*}{ Experiment } & \multirow{2}{*}{ Treatment } & \multirow{2}{*}{ 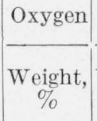 } & \multicolumn{2}{|c|}{ Hydrogen } \\
\hline & & & Weight, & $\begin{array}{l}\text { Vol- } \\
\text { ume a }\end{array}$ \\
\hline A... & Copper stripped from chromium .. & 0.42 & 0.028 & 22 \\
\hline B... & As deposited, on copper $\ldots$ & .36 & .048 & 38 \\
\hline C.......... & As deposited, on steel & ...... & .044 & 35 \\
\hline D & Stood 2 months & .43 & .044 & 35 \\
\hline E... & Stood 3 months .................... & .39 & .046 & 37 \\
\hline F. & Heated at $200^{\circ} \mathrm{C}$ for 1 hour... & $\ldots$. & .024 & 19 \\
\hline $\mathrm{G}_{--}$ & Heated at $300^{\circ} \mathrm{C}$ for 1 hour... & .47 & .018 & 14 \\
\hline $\mathrm{H}_{-.}$ & Heated at $350^{\circ} \mathrm{C}$ for 1 hour & $\ldots$ & .008 & 6 \\
\hline I $\ldots \ldots \ldots$ & Heated at $400^{\circ} \mathrm{C}$ for 1 hour & .46 & .005 & 4 \\
\hline $\mathbf{J}_{-.}$ & Heated at $450^{\circ} \mathrm{C}$ for 1 hour & & .001 & 1 \\
\hline K & Heated at $800^{\circ} \mathrm{C}$ for 1 hour & $\ldots$ & .002 & 2 \\
\hline L . ... & Heated at $1,200^{\circ} \mathrm{C}$ for 1 hour $\ldots . .$. & ? & .002 & 2 \\
\hline
\end{tabular}

a Volume of hydrogen per volume of chromium.

In some analyses the chromium deposits were allowed to remain on the copper tube upon which they had been plated; in others the copper was dissolved away with nitric or chromic acid. According to Gernet's data [13] no hydrogen escapes from chromium during solution of the copper. The single experiment (A) recorded in table 3 indicates some loss of hydrogen during this removal of copper.

\section{Effect of Temperature and Current Density on Hydrogen and Oxygen Content}

The temperature of deposition of chromium has the most important effect upon the content of oxygen in the deposit, as shown in table 2 and in figure 7. As the temperature of deposition is increased, the percentage of oxygen diminishes from 0.87 percent for deposits plated at $30^{\circ} \mathrm{C}$ to about 0.03 percent for deposits at $100^{\circ} \mathrm{C}$. The hydrogen content of the deposits show less regularity, but in general it parallels the oxygen content and decreases as the temperature of the plating solution is raised. The hydrogen contents of the deposits, with one exception, range from about 0.06 percent (50 volumes) for specimens plated at $50^{\circ} \mathrm{C}$ to about 0.01 percent (9 volumes) for deposits at $100^{\circ} \mathrm{C}$. This general trend with temperature agrees with the findings of Gernet [13], but not with those of Makariewa and Birükoff [26] who found an increase in hydrogen for deposits plated between $30^{\circ}$ and $60^{\circ} \mathrm{C}$ at 13

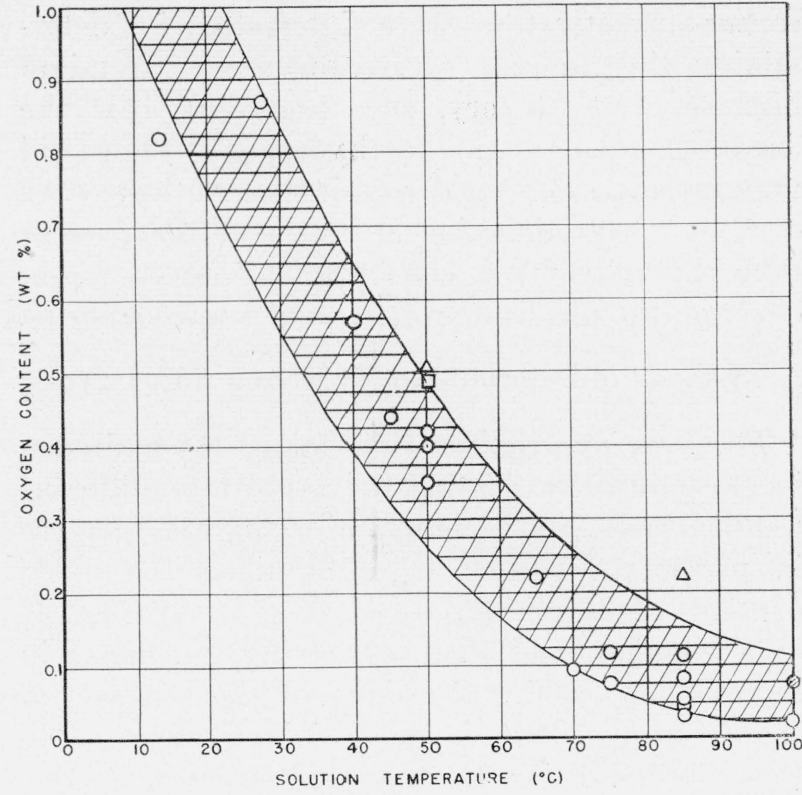

Figure 7. Effect of temperature of plating bath on the oxygen content of chromium deposits.

Standard, $\bigcirc$; dilute, ; concentrated, $\square$; fluoride, $\triangle$.

$\operatorname{amp} / \mathrm{dm}^{2}{ }^{2}$ The effect of current density on the oxygen content of the deposits is surprisingly slight, inasmuch as one would expect more basic material to be included in the deposits at higher current densities. The deposits obtained at $50^{\circ}$ C, (table 2, deposits 8, 12, and 14) and at $65^{\circ}$ C (deposits 18, 19, and 21) show virtually no increase in oxide content as the current density is raised from 20 to $200 \mathrm{amp} / \mathrm{dm}^{2}$ At $85^{\circ} \mathrm{C}$, over the range of current density from 40 to 120 $\mathrm{amp} / \mathrm{dm}^{2}$ (deposits 31 to 33 ), the oxygen content decreases.

The hydrogen content of the deposits increases moderately with current density, as indicated by deposits 8,12 , and 14 prepared at $50^{\circ} \mathrm{C}$, and 42 and 43 prepared at $85^{\circ} \mathrm{C}$. This is in general agreement with the results of Makariewa and Birükoff, who analyzed deposits plated at $45^{\circ}$ $\mathrm{C}$ and found that the hydrogen increased from 30 volumes to 48 volumes as the current density increased from 3 to $120 \mathrm{amp} / \mathrm{dm}^{2}$; but the change was slightly between 25 and $120 \mathrm{amp} / \mathrm{dm}^{2}$. The general conclusion from this work, and that of Gernet [13] is that the hydrogen content, like the oxygen content of chromium changes only slightly with a several-fold change in current density.

The data in table 2 as a whole show no relation between cathode current efficiency and oxygen or 
hydrogen content. For example, at a current efficiency of 15 to 17 percent, deposits can be obtained ranging in hydrogen content from 0.01 to 0.06 percent and in oxygen content from 0.04 to 0.6 percent. However, if the variables of plating are more restricted, the content of hydrogen and oxygen in the deposit is found to increase with current efficiency. This is illustrated by deposits $32,39,43$, and 55 all plated at a current density of $80 \mathrm{amp} / \mathrm{dm}^{2}$ and a temperature of $85^{\circ} \mathrm{C}$ but from solutions of different compositions. As the cathode current efficiency rises from 10 to 27 percent, the hydrogen content increases from 0.014 percent (11 volumes) to 0.034 percent (27 volumes) and the oxygen content from 0.05 to 0.24 percent. One might have expected a higher hydrogen content at low current efficiencies, because a larger excess of hydrogen is produced.

The content of hydrogen in deposit 38, table 2, is abnormally high. This deposit was one of those that spalled. It seems likely that the spalling is the result of a high internal pressure generated by the large excess of hydrogen. The phenomenon is similar to the blistering of nickel foil that occurs when hydrogen is eathodically discharged upon it [28].

\section{Removal of Hydrogen from Chromium by Heating}

The evidence cited above, in connection with the discussion of analytical methods, shows that at room temperature hydrogen does not readily leave the deposit, but that it readily leaves when the deposit is heated. The determination of the quantity of hydrogen expelled from chromium at various temperatures has been the subject of investigations by Guichard [16], Makariewa and Birukoff [26], and Gernet [13], all of whom were interested in the relation between hydrogen content and hardness of the deposit. In our study of the hydrogen content, specimens of chromium were sealed in evacuated tubes and heated, and the residual hydrogen in the deposit was determined by the vacuum fusion method. This latter procedure has the disadvantage, as compared to the vacuum extraction method of the other investigators, that a separate specimen must be used for each temperature investigated.

The data obtained by the vacuum fusion method are shown in table 3 , and are plotted in figure 8, along with data from the work of Gui- chard [16] and Makariewa [26]. The main features of the expulsion of hydrogen from chromium are that the hydrogen escapes gradually as the temperature is raised, until at about $400^{\circ} \mathrm{C}$ virtually all of the hydrogen has been removed. It is to be noted that only a certain proportion of the hydrogen escapes at a given temperature. Holding the chromium at a given temperature for an indefinite period apparently will not cause a further appreciable loss of hydrogen. Guichard heated his specimens for as long as 3 days to obtain the maximum removal of hydrogen, but his curve is not far different from that of Makariewa and our own curve where the heating was only of 1 hour's duration.

Hydrogen is expelled from chromium as the free element and not as water. This has been shown by analyses of the evolved gas by Makariewa and Guichard $[26,16]$ and by the fact that the oxide content of chromium does not change as a result of heating. Evidence for the latter is that the method of Adcock, which involves heating the specimen to a high temperature before analyses, gives the same oxide content as the vacuum fusion method. The data given in table 3 for specimens

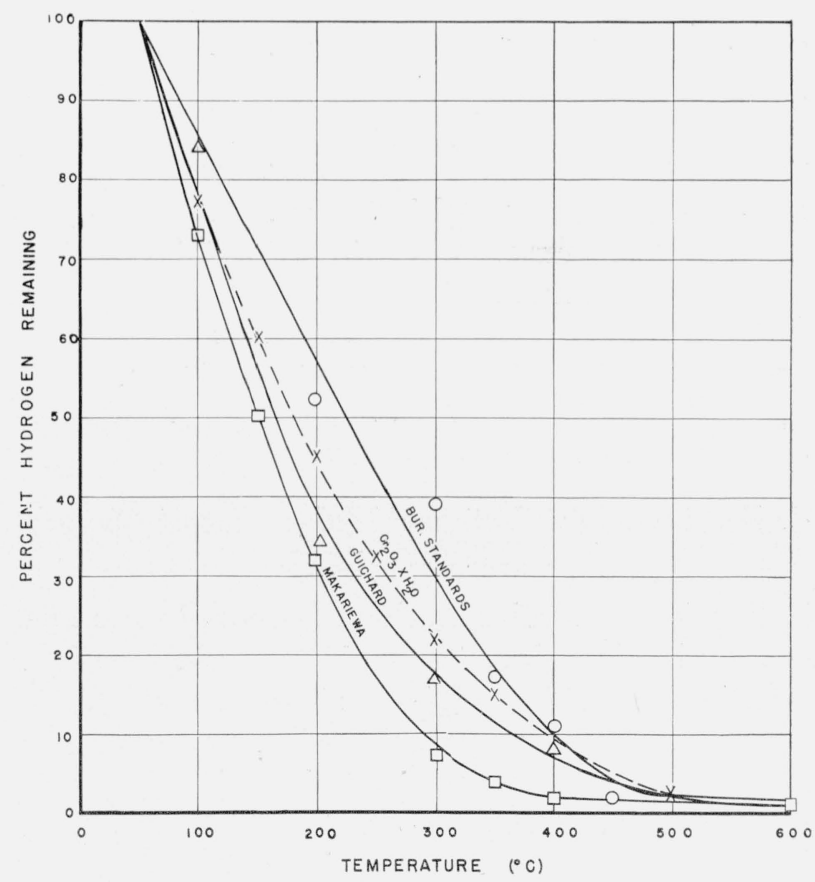

Figure 8. Percentage of the initial amount of hydrogen, remaining in chromium after annealing at various temperatures.

The curve marked " $\mathrm{Cr}_{2} \mathrm{O}_{3}$ " represents the percentage of water remaining in hydrous chromic oxide, which initially contained 3 to 5 molecules of water. 
heated to different temperatures show the same oxygen content.

TABLE 4. Hydrogen and oxygen content of electrodeposited metals s

\begin{tabular}{|c|c|c|c|c|c|c|c|c|}
\hline \multirow[t]{2}{*}{ Deposit } & \multirow[t]{2}{*}{ Bath type } & \multirow{2}{*}{ 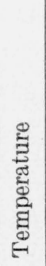 } & \multirow{2}{*}{ 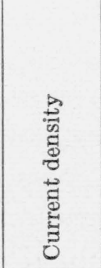 } & \multirow[b]{2}{*}{$\begin{array}{l}\text { 명 } \\
\text { on } \\
\hat{\mathscr{d}} \\
0\end{array}$} & \multirow{2}{*}{ 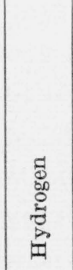 } & \multirow{2}{*}{ 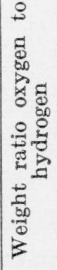 } & \multicolumn{2}{|c|}{$\begin{array}{l}\text { Vol- } \\
\text { ume } \\
\text { hydro- } \\
\text { gen } \\
\text { (per } \\
\text { vol. } \\
\text { metal) }\end{array}$} \\
\hline & & & & & & & E⿱ & 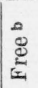 \\
\hline Nickel_ & Watts' pH 5.2 & ${ }^{\circ} \mathrm{C}$ & amp/dm 2 & $\begin{array}{r}w t, \% \\
0.004\end{array}$ & $\begin{array}{l}w t, \% \\
0.0017\end{array}$ & 2 & 1. 7 & 1 \\
\hline Do & Watts' pH 5.8. & 30 & 2 & .021 & .0060 & 4 & 6 & 5 \\
\hline Do $\ldots \ldots$ & $\begin{array}{c}\text { High sulfate, } \\
\text { pH } 6.6 .\end{array}$ & 30 & 2 & .014 & .0053 & 3 & 5 & 4 \\
\hline $\begin{array}{l}\text { Nickel - tungsten } \\
\quad(5 \% \mathrm{~W}) \text {. }\end{array}$ & Ammoniacal & 90 & 2 & .006 & .004 & 2 & 4 & 4 \\
\hline Nickel-tungsten & ...... do & 30 & 2 & .360 & .042 & 9 & 42 & 20 \\
\hline Cobalt_......... & Chloride, $\mathrm{pH} 4$ & 30 & 2 & .049 & .004 & 12 & 4 & 1 \\
\hline $\begin{array}{l}\text { Cobalt - tungsten } \\
\quad(14 \% \mathrm{~W})\end{array}$ & $\begin{array}{l}\text { Ammoniacal } \\
\text { tartrate. }\end{array}$ & 90 & 2 & .084 & .011 & 8 & 11 & 6 \\
\hline $\begin{array}{l}\text { Cobalt - tungsten } \\
(22 \% \mathrm{~W}) \text {. }\end{array}$ & ..... do & 25 & 2 & 1.14 & .064 & 18 & 64 & 6 \\
\hline $\begin{array}{l}\text { Cobalt - tungsten } \\
(18 \% \mathrm{~W}) .\end{array}$ & .....do & 90 & 5 & 0.165 & .014 & 12 & 14 & 4 \\
\hline $\begin{array}{l}\text { Cobalt - tungsten } \\
(25 \% \mathrm{~W})\end{array}$ & ..... do & 90 & 2 & .087 & .008 & 11 & 8 & 3 \\
\hline $\begin{array}{l}\text { Cobalt - tungsten } \\
(23 \% \mathrm{~W}) \text {. }\end{array}$ & _..._do do & 90 & 2 & 064 & .009 & 7 & 9 & 5 \\
\hline $\begin{array}{l}\text { Cobalt - tungsten } \\
\quad(42 \% \mathrm{~W}) .\end{array}$ & $\begin{array}{l}\text { Ammoniacal } \\
\text { citrate. }\end{array}$ & 90 & 2 & .430 & .027 & 16 & 27 & 0 \\
\hline $\begin{array}{l}\text { Cobalt - tungsten } \\
(29 \% \text { W). }\end{array}$ & ..... do & 90 & 2 & .177 & .012 & 15 & 12 & 1 \\
\hline Iron & $\begin{array}{l}\text { Ferrous chlor- } \\
\text { ide. }\end{array}$ & 95 & 10 & .020 & .001 & 20 & 1 & 0 \\
\hline $\begin{array}{l}\text { Iron - tungsten } \\
\qquad(50 \% \mathrm{~W}) \text {. }\end{array}$ & $\begin{array}{l}\text { Ammoniacal } \\
\text { citrate. }\end{array}$ & 90 & 3 & .043 & .002 & 22 & 2 & 0 \\
\hline Avg & & & & & & 10.5 & & $\ldots$ \\
\hline
\end{tabular}

- Data in this table taken from a paper on the electrodeposition of tungsten alloys now in course of publication.

b Calculated on basis of oxygen combining with hydrogen in weight ratio of 16 , i. e., as $\mathrm{OH}$.

\section{Form and Distribution of Hydrogen and Oxygen in Electrodeposits}

The form and distribution of the hydrogen and oxygen in chromium are subjects for speculation, as neither metallographic nor X-ray studies have thrown much light on this point. Because the role played by these elements is so important in determining the properties, not only of chromium, but also of other electrodeposits, the subject will be discussed in some detail and pertinent data concerning other electrodeposits will be introduced.

The most plausible explanation for the inclusion of oxygen in electrodeposits is the formation of basic compounds in the cathode layer, the $\mathrm{pH}$ of which is always higher than that of the body of solution. These basic compounds may be adsorbed, or deposited as charged colloidal particles, on the cathode where they interfere with grain growth in the same manner as addition agents, and thus cause the formation of small crystals, which are characteristic of chromium deposits. From its interference with grain growth, it seems likely that the basic impurity would be concentrated on the surface of the grains in a finely dispersed form.

There is not much evidence on the nature of the basic compound present in electrolytic chromium. The suggestion that the oxygen content of chromium comes from plating solution that is trapped in cracks is untenable. Adcock found no traces of chromates on extracting a deposit with water. Furthermore, the high-temperature deposits have no cracks with which to trap solution, and yet they contain oxide. The best evidence on the nature of the oxygen compound in chromium comes from the work of Cohen [6], who isolated films of a basic material, from chromium deposits by a process of electrolytic etching. This material came mainly from the cracks and inclusions, but accounted for less than a tenth of the oxygen that was probably present in the deposit. The bulk of the basic compound, therefore, must be very finely dispersed, but there is no reason to expect that it would differ in composition from the material isolated by Cohen, which was found by analyses and $\mathrm{X}$-ray examination to be chromic oxide. It is very likely a hydrous chromic oxide, $\mathrm{Cr}_{2} \mathrm{O}_{3} \cdot \mathrm{nH}_{2} \mathrm{O}$, as anhydrous chromic oxide is not soluble in acids, and it is known that chromium deposits dissolve completely in dilute hydrochloric acid. It may be noted that chromic hydroxide, $\mathrm{Cr}(\mathrm{OH})_{3}$, does not exist [35].

To determine the state in which hydrogen exists in chromium requires a more extensive examination of the evidence than was necessary for oxygen. As hydrogen is given off as the free element when chromium is heated, most of the investigators of the hydrogen content of chromium have tacitly assumed that all of the hydrogen was present as the uncombined element. This conclusion is contradictory to the idea, just outlined, that the basic materials that are adsorbed on the cathode are either hydroxides or hydrous oxides. It is unlikely that oxides can separate 
from a water solution without carrying along basic $\mathrm{OH}$ groups or adsorbed water. The evidence to be cited here indicates that part of the hydrogen is combined with oxygen in basic compounds, and that the remainder exists as the free element.

The reasons against the belief that all of the hydrogen is present as the free element will be considered first. Martin [25] has shown that the equilibrium solubility of hydrogen in chromium is very small, probably about 0.00001 percent. Therefore, the gas cannot be in true solution in the chromium. . It might be assumed that all of the hydrogen is present in chromium in the same condition that it is present in cathodically treated iron or nickel (for example between slip planes). However, if this were the case, most of the hydrogen would gradually escape on standing or gentle warming, as it does from iron and nickel, whereas it is still present in chromium after many months.

The best evidence that the oxygen is combined with part of the hydrogen comes from chemical analyses, which show that a simple relation exists between the amount of hydrogen and oxygen in most electrodeposits. Previously, sufficient data on the content of hydrogen and oxygen in electrodeposits have not been available in the literature to permit drawing conclusions. In addition to the data for chromium in table 2 , data are given for a variety of electrodeposits in table 4 .

The data in tables 2 and 4 as a whole show that the weight ratio of oxygen to hydrogen varies from 2 to 22 , with an average of 10 . The average ratio is 8 for the chromium deposits and 11 for the others. The majority of deposits have a ratio between 8 and 12 . It is surprising that the ratio should be so similar for solutions differing as widely in type as hexavalent and trivalent chromium solutions; moderately acid nickel, cobalt, and iron solutions; and ammoniacal alloy solutions. The range of oxygen content for all of these deposits is from 0.004 to 0.8 percent, a 200 fold variation. The range of hydrogen content is from 0.001 to 0.06 percent, which is a 60 -fold variation. If the oxygen and hydrogen contents were entirely unrelated, their ratios might vary several thousand-fold. The relatively small variation of the ratio is strong evidence that the oxygen is combined with the hydrogen in electrodeposits.

It would be of interest to determine the proportion of free and combined hydrogen in electro- deposits, but in general we do not know the composition of the basic inclusions. The ratio of oxygen to hydrogen could vary from 8 for water, 16 for $\mathrm{OH}$ groups, to 32 for materials such as basic chromium chromate. To estimate the upper limit of the content of free hydrogen in electrodeposits, it will be assumed that the oxygen is combined with hydrogen in the weight ratio of 16 , and that the remainder of the hydrogen is free. On this assumption, it is found that the content of free hydrogen in electrodeposits other than chromium is less than 6 volumes $(0.006 \%)$ and is usually less than half of the total hydrogen present. The excess of hydrogen in most chromium deposits is less than 15 volumes.

One difficulty yet to be explained is why, on heating, all of the hydrogen is expelled from chromium in the free state, instead of partly as water produced by the decomposition of basic material. Thermodynamic calculations (made by D. D. Wagman of this Bureau) show that water vapor will react with chromium or iron at $100^{\circ} \mathrm{C}$ to yield hydrogen, and hence no evolution of water should be expected. The ratio of the partial pressures of hydrogen to water at $100^{\circ} \mathrm{C}$ in the presence of chromium is $10^{15}$, and in the presence of iron, $10^{2}$, which indicates that the formation of hydrogen from water by chromium is very greatly favored. In this connection, the curve marked " $\mathrm{Cr}_{2} \mathrm{O}_{3}$ " in figure 8, representing the loss of water from hydrous chromic oxide (containing 3 to 5 molecules of water), is of interest. Not only is the curve similar in shape to that for the removal of hydrogen from chromium, but the temperature at which all the water is driven off is the same as that at which all the hydrogen is expelled from chromium (about $400^{\circ} \mathrm{C}$ ). This may be only a double coincidence, but it suggests that the expulsion of hydrogen from chromium on heating involves first a liberation of water vapor from the inclusions of hydrous chromic oxide.

\section{Density of Chromium}

The density of electrodeposited chromium has been determined previously by a number of investigators, but no systematic study has been made of the effect of the conditions of deposition on the density. The density of chromium is not of interest in itselt, but if it can be correlated with other properties, it may throw light on the struc- 
ture of the deposit. The increase in density of chromium on heating is of particular interest.

The density of chromium was measured at $28^{\circ}$ $\mathrm{C}$ by the method of loss in weight, using tetrabromoethane (density 2.96). The density of chromium, calculated from the value of its cell parameter, $2.878 \mathrm{~A}$, for a body-centered cube, is $7.20 \mathrm{~g} / \mathrm{cm}^{3}$. The data in table 5 indicate that the density of electrodeposited chromium is, with a few exceptions, less than that of pure annealed

TABLE 5. Density of electrodeposited chromium

\begin{tabular}{|c|c|c|c|c|c|c|c|}
\hline \multirow{3}{*}{$\begin{array}{l}\text { De- } \\
\text { pos- } \\
\text { it } \\
\text { No. }\end{array}$} & \multirow{3}{*}{ Bath } & \multirow{3}{*}{$\begin{array}{l}\text { Tem- } \\
\text { pera- } \\
\text { ture }\end{array}$} & \multirow{3}{*}{$\begin{array}{l}\text { Current } \\
\text { density }\end{array}$} & \multicolumn{4}{|c|}{ Density } \\
\hline & & & & \multirow{2}{*}{$\begin{array}{c}\text { As } \\
\text { de- } \\
\text { pos- } \\
\text { ited }\end{array}$} & \multicolumn{2}{|c|}{$\begin{array}{l}\text { Heated } 1 \\
\text { hour }\end{array}$} & \multirow{2}{*}{$\begin{array}{l}\text { a Cor- } \\
\text { rected } \\
\text { for } \\
\text { oxide } \\
\text { con- } \\
\text { tent }\end{array}$} \\
\hline & & & & & $\begin{array}{c}450^{\circ} \\
\mathrm{C}\end{array}$ & $\frac{1,200^{\circ}}{\mathrm{C}}$ & \\
\hline 1 & Standard & ${ }^{\circ} \mathrm{C}$ & $a m p / d m^{2}$ & $\mathrm{~g} / \mathrm{cm}^{3}$ & $\mathrm{~g} / \mathrm{cm}^{3}$ & $\mathrm{~g} / \mathrm{cm}^{3}$ & $\mathrm{~g} / \mathrm{cm}^{3}$ \\
\hline $\begin{array}{l}1 \\
2\end{array}$ & $\begin{array}{l}\text { Standard } \\
\text { do }\end{array}$ & $\begin{array}{l}30 \\
30\end{array}$ & $\begin{array}{r}5 \\
10\end{array}$ & $\begin{array}{l}6.90 \\
6.92\end{array}$ & 7.08 & 7.12 & $\begin{array}{r}7.19 \\
-\end{array}$ \\
\hline 3 & . do . . . & 40 & 15 & 6.94 & 7. 10 & 7.13 & 7. 18 \\
\hline 6 & _._. do _... & 50 & 5 & 7.06 & 7.12 & 7.17 & ... \\
\hline 7 & _._. do $\ldots$ & 50 & 10 & 7.06 & -... & 7.17 & \\
\hline 8 & _._. do .... & 50 & 20 & 7.05 & 7.11 & 7.15 & 7.18 \\
\hline 9 & $\ldots$ do _... & 50 & 30 & 7.01 & 7. 10 & 7.14 & $\ldots$ \\
\hline 10 & _. _. do . . . . & 50 & 40 & 7.01 & 7.11 & 7.14 & . \\
\hline 11 & . do & 50 & 60 & 6.98 & $\ldots$ & . & - \\
\hline 12 & .... do . . & 50 & 80 & 6.99 & 7.10 & 7.13 & 7.16 \\
\hline 14 & _.... do ... & 50 & 200 & 6.99 & & & \\
\hline 19 & $\ldots$. . do ... & 65 & 40 & 7.11 & 7. 14 & 7.17 & 7.19 \\
\hline 26 & $\ldots$ do $_{\ldots} \ldots$ & 75 & 60 & 7.17 & 7.15 & 7.19 & 7. 20 \\
\hline 32 & . do & 85 & 80 & 7.17 & 7. 20 & 7.19 & 7. 20 \\
\hline 35 & $\ldots$...... do _... & 90 & 80 & 7.10 & & 7. 18 & \\
\hline 36 & $\ldots$. $d o_{\ldots} \ldots$ & 95 & 80 & 7.03 & & 7. 19 & \\
\hline 37 & ..... do ..... & 100 & 80 & 7.04 & & 7.16 & -..- \\
\hline 40 & Dilute.... & 50 & 10 & 7.02 & & & \\
\hline 41 & $\ldots$..... do ... & 50 & 20 & 7.01 & & & $\cdots$ \\
\hline 42 & _... do ..... & 85 & 20 & 7.18 & & 7.18 & 7.19 \\
\hline 43 & _._. do . . . & 85 & 80 & 7.16 & & 7.19 & 7.20 \\
\hline 45 & $\ldots$..... do_... & 100 & 80 & 7.20 & & 7.19 & 7.20 \\
\hline 46 & . & 100 & 100 & 7.21 & & 7.22 & ..... \\
\hline 48 & Concentrated & 50 & 20 & 7.07 & & & \\
\hline 51 & Flouride-1 & 50 & 30 & 6.98 & & 7.09 & 7.14 \\
\hline 52 & ..... do . . . . & 50 & 40 & 7.05 & & & \\
\hline 53 & .... do & 85 & 20 & 7. 18 & & & ... \\
\hline 55 & ... do _.... & 85 & 80 & 7.14 & & 7.18 & 7. 20 \\
\hline 57 & Flouride $-3 .$. & 85 & 20 & 7.18 & & 7.21 & \\
\hline 58 & Flouride-4 & 85 & 20 & 7.17 & & & \\
\hline 63 & Flouride-5 & 85 & 60 & 7. 18 & & & \\
\hline 64 & Flouride- $6 . . .$. & 85 & 80 & 7.15 & . & . & ..... \\
\hline 66 & Trivalent... & & & 6.97 & & 7.14 & 7. 19 \\
\hline
\end{tabular}

a Density of deposits heated to $1,200^{\circ} \mathrm{C}$, corrected for oxide content, assuming the oxide to be $\mathrm{Cr}_{2} \mathrm{O}_{3}$. chromium, and varies with the conditions of deposition, from 6.90 to $7.20 \mathrm{~g} / \mathrm{cm}^{3}$, a range of about 4 percent.

\section{Factors Affecting Density}

The density of a deposit is lowered by a number of factors, such as content of oxygen and hydrogen, cracks and inclusions, and strains. The curve in figure 9 illustrates the increase in density of chromium as the oxygen content decreases. Figure 18 , b, shows that the density decreases as the current density is raised. As the deposits obtained at the lower temperatures have cracks and/or inclusions, they have a lower density than those deposited at elevated temperatures, which are relatively free from these defects. Exceptions to this statement are the spalled deposits, such as 36 and 37 (table 5), which had an abnormally low density, as might have been expected from their lack of soundness.

Cold-worked metals have a lower density than annealed metals because of internal strain represented by a distortion of the space lattice. Because electrodeposited metals are, effectively, in a more severely cold-worked state than an ordinary cold-worked metal, it might be assumed that their density would be affected. However, the effect of cold work on the density of metals is quite small [10, p. 137], usually less than 0.1 percent. If the lattice expansion of 0.3 percent (as compared with chromium annealed at $1,500^{\circ} \mathrm{C}$ ) observed by Woods [38] for bright chromium

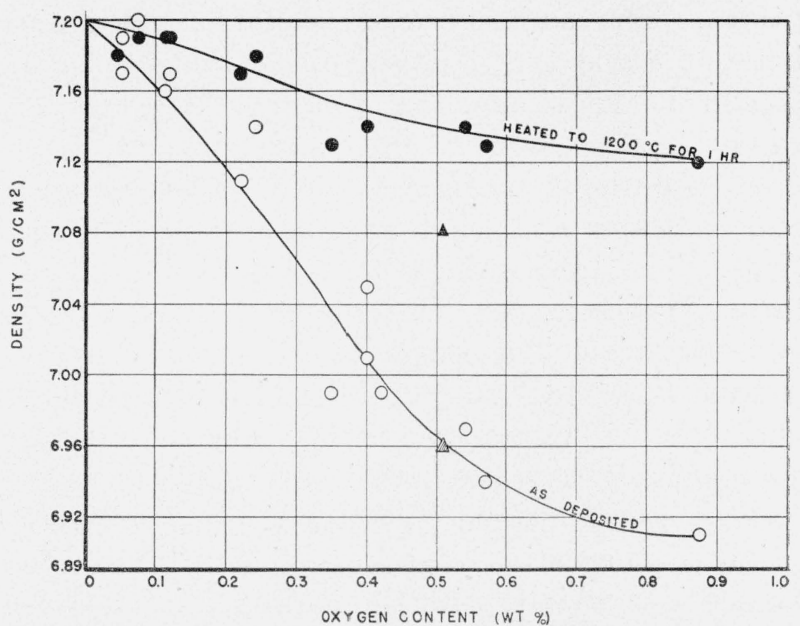

Figure 9. Relation between density and oxygen content of chromium deposits.

Standard, $\bigcirc$; fluoride, $\triangle$; heat treatment. 
were all attributed to internal strain, this would correspond to a lowering of the density of chromium by only $0.02 \mathrm{~g} / \mathrm{cm}^{3}$.

\section{Effect of Annealing on Density}

The density of chromium increases on annealing, as shown in table 5. This change in density was first observed by Hidnert [15] and Jenicek [17] in the form of a contraction of a chromium tube on heating. Jenicek showed, and we have confirmed his observation, that the contraction of chromium occurs uniformly in all directions. Because the dimensional changes are isotropic, it was found simpler to follow them by measuring the change in density instead of the contraction.

The change in density on heating is gradual. For those deposits that undergo a large change in density on heating, most of the change occurs below $450^{\circ} \mathrm{C}$. This indicates that the expulsion of the hydrogen must be responsible for a large part, but not necessarily all, of the increase in density. The density of most deposits after annealing at $1,200^{\circ} \mathrm{C}$ is still below $7.20 \mathrm{~g} / \mathrm{cm}^{3}$, the value for pure chromium. However, if a correction is made for the presence of $\mathrm{Cr}_{2} \mathrm{O}_{3}$ (last column of table 5) the density of chromium is found to be between 7.18 and $7.20 \mathrm{~g} / \mathrm{cm}^{3}$. Apparently at $1,200^{\circ} \mathrm{C}$ most of the cracks and defects in chromium are eliminated by sintering.

\section{Hardness of Chromium Deposits}

Hardness is the physical property of chromium of most practical importance. It has, therefore, been the subject of considerable study, not only because of this, but also because of the theoretical interest in the great difference in hardness between electrolytic and cast chromium. If the hardness of chromium is correlated with other properties, it may serve to define the general character of a deposit.

The hardness of chromium was measured on a polished cross section of a deposit plated on a copper tube. The thickness of the deposit varied from 0.075 to $0.25 \mathrm{~mm}$ (0.003 to 0.01 in.). A few check measurements showed that the same hardness was obtained on the cross section as on the surface parallel to the cathode. The hardness was measured with a Knoop diamond indenter, using loads up to $500 \mathrm{~g}$. Most of these measurements were made by Irene C. Minor of the Metallurgy Division of this Bureau.

The data in table 6 show that the hardness of chromium may vary from 300 Knoop to 1,000 Knoop, depending on the conditions of deposition. In comparison, the hardness of cast chromium has been given as ranging from 70 Brinell to 130 Brinell.

TABLE 6. Hardness of electrodeposited chromium

\begin{tabular}{|c|c|c|c|c|}
\hline $\begin{array}{l}\text { De- } \\
\text { posit } \\
\text { No. }\end{array}$ & Bath & $\begin{array}{l}\text { Temper- } \\
\text { ature }\end{array}$ & $\begin{array}{l}\text { Current } \\
\text { density }\end{array}$ & $\begin{array}{l}\text { Hard- } \\
\text { ness }\end{array}$ \\
\hline 1 & Standard & ${ }^{\circ} \mathrm{C}$. & $\begin{array}{r}a m p / d m^{2} \\
5\end{array}$ & $\begin{array}{r}\text { Knoop } \\
985\end{array}$ \\
\hline 2 & . & 30 & 10 & 960 \\
\hline 3 & . do ... & 40 & 15 & 905 \\
\hline 5 & do & 45 & 25 & 900 \\
\hline 6 & .... do _... & 50 & 5 & 920 \\
\hline 7 & .... do & 50 & 10 & 960 \\
\hline 8 & .... do & 50 & 20 & 920 \\
\hline 9 & do & 50 & 30 & 940 \\
\hline 10 & ..... do & 50 & 40 & 880 \\
\hline 11 & ... do & 50 & 60 & 880 \\
\hline 12 & .... do & 50 & 80 & 875 \\
\hline 14 & ..... do & 50 & 200 & 750 \\
\hline 15 & ..... do & 60 & 40 & 745 \\
\hline 16 & do & 65 & 10 & 600 \\
\hline 17 & $\ldots$ do ..... & 65 & 20 & 625 \\
\hline 18 & do do & 65 & 30 & 800 \\
\hline 19 & ... do & 65 & 40 & 975 \\
\hline 20 & do . . & 65 & 80 & 825 \\
\hline 21 & do $\ldots$ & 65 & 100 & 925 \\
\hline 22 & do ....... & 70 & 40 & 600 \\
\hline 23 & ..... do _. & 70 & 80 & 875 \\
\hline 24 & ..... do & 70 & 100 & 870 \\
\hline 25 & .... do & 75 & 50 & 580 \\
\hline 26 & $\ldots$ do $\ldots$ & 75 & 60 & 685 \\
\hline 27 & do & 75 & 80 & 885 \\
\hline 28 & $\ldots$ do & 75 & 100 & 650 \\
\hline 29 & . do . . . & 85 & 20 & 325 \\
\hline 30 & $\ldots$ do $\ldots$ & 85 & 40 & 425 \\
\hline 31 & $\ldots$ do $\ldots$ & 85 & 60 & 475 \\
\hline 32 & .... do ... & 85 & 80 & 550 \\
\hline 33 & ..... do . & 85 & 120 & 550 \\
\hline 35 & ..... do & 90 & 80 & 575 \\
\hline 36 & $\ldots$ do & 95 & 80 & 525 \\
\hline 37 & .... do .... & 100 & 80 & 670 \\
\hline 39 & $\mathrm{High} \mathrm{SO}_{4}$ & 85 & 80 & 625 \\
\hline 41 & Dilute _. & 50 & 20 & 900 \\
\hline 42 & ... do & 85 & 20 & 325 \\
\hline 43 & ... do $\ldots$ & 85 & 80 & 500 \\
\hline 45 & .... do ..... & 100 & 80 & 310 \\
\hline 48 & Concentrated & 50 & 20 & 675 \\
\hline $50 \mathrm{a}$ & Fluoride. & 85 & 60 & 885 \\
\hline
\end{tabular}


TABLE 6. Hardness of electrodeposited chromium-Con.

\begin{tabular}{|c|c|c|c|c|}
\hline $\begin{array}{l}\text { De- } \\
\text { posit } \\
\text { No. }\end{array}$ & Bath & $\begin{array}{l}\text { Temper- } \\
\text { ature }\end{array}$ & $\begin{array}{l}\text { Current } \\
\text { density }\end{array}$ & $\begin{array}{l}\text { Hard } \\
\text { ness }\end{array}$ \\
\hline 51 & Fluoride-1 & ${ }^{\circ} \mathrm{C}$. & $\begin{array}{c}a m p / d m^{2} \\
30\end{array}$ & $\begin{array}{l}\text { Knoop } \\
\quad 900\end{array}$ \\
\hline 53 & ..... do.. & 85 & 20 & 470 \\
\hline 54 & .... do & 85 & 40 & 836 \\
\hline 55 & do & 85 & 80 & 800 \\
\hline 63 & Fluoride-5 . . & 85 & 60 & 445 \\
\hline 66 & Trivalent... & & & 710 \\
\hline
\end{tabular}

\section{Effect of Temperature and Current Density}

In general softer deposits are obtained at low current densities and at elevated temperatures: This simple statement will require considerable modification and restriction in the light of the following discussion.

At a given temperature, deposits of a considerable range of hardness can be obtained by a suitable choice of both composition and plating conditions. Thus at $65^{\circ} \mathrm{C}$, the hardness may vary from 600 to 825 Knoop. (Table 6, deposits 16 and 20). However, if the optimum conditions for producing soft deposits are selected for each temperature, a softer deposit can be obtained at an elevated temperature than at a lower temperature. As shown in figure 10, there is a fairly well defined lower limit to the hardness at each temperature but not an upper limit. Almost as hard a deposit can be obtained at $70^{\circ} \mathrm{C}$ as at $50^{\circ} \mathrm{C}$, but such hard deposits are not obtainable at still more elevated temperatures.

If the deposits obtained from the "standard" plating solution are considered, more specific effects of temperature and current density on hardness are apparent. This is shown by the curves in figure 10, b. Cymboliste [7], and Hume-Rothery and Wylie [40] have also studied the effect of temperature and current density on the hardness of deposits from the standard solution. Curves from their papers are shown in figures 11 and 12 and they show that at a given current density the hardness of the deposit reaches a maximum at a certain temperature. If the conditions of plating were to the left of the maximum, then an increase of temperature would result in a harder deposit, and an increase of current density in a softer deposit. These effects are opposite to the general trends mentioned at the start of this discussion. Cymboliste and Hume-Rothery differ as to the temperature at which the maximum hardness occurs. Cymboliste's curves show the maximum to be at $50^{\circ} \mathrm{C}$ for all current densities, whereas Hume-Rothery's reports show that the maximum is at a different temperature for each current, density. Our data in figure $10, b$, confirm the observations of Cymboliste, i. e., the curve represent-

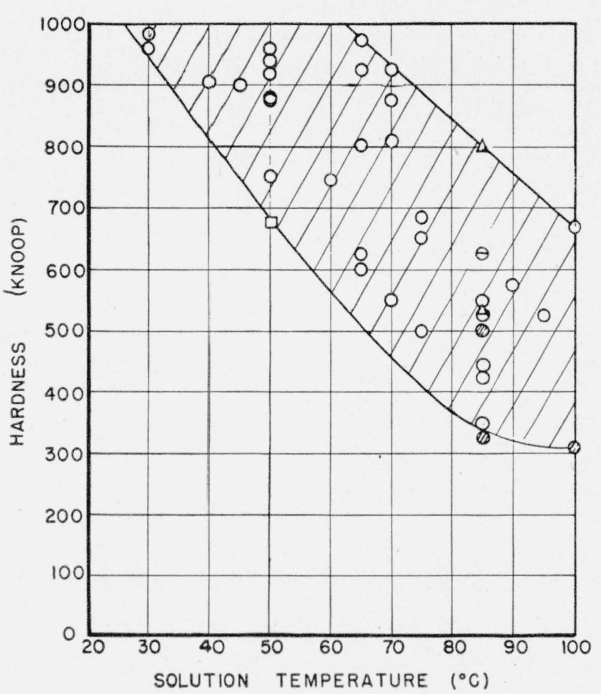

a

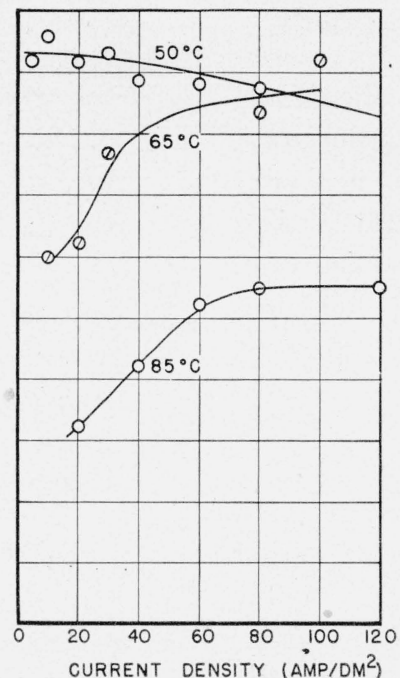

b

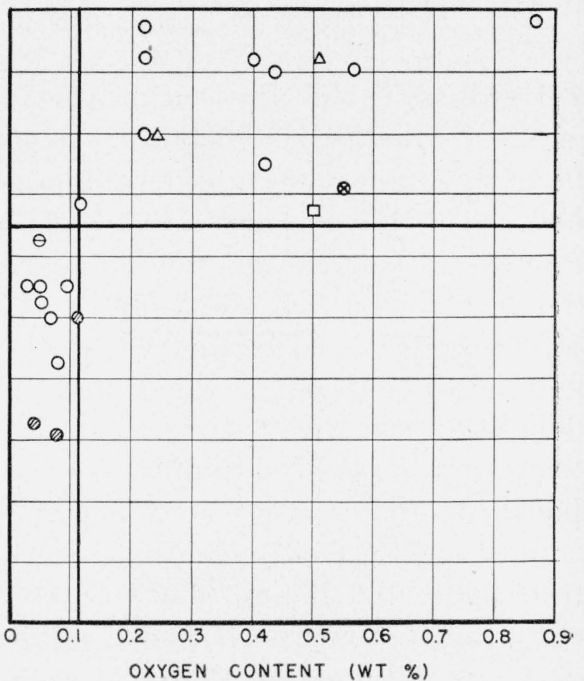

C

Figure 10. Hardness of electrodeposited chromium.

$a$, Effect of temperature of deposition on hardness of chromium; $b$, effect of current density on the hardness of chromium, deposited from the standard bath; $\boldsymbol{c}$, relation between hardness and oxygen content of chromium deposits-standard, $\bigcirc$; dilute, $;$; fluoride, $\triangle$. 


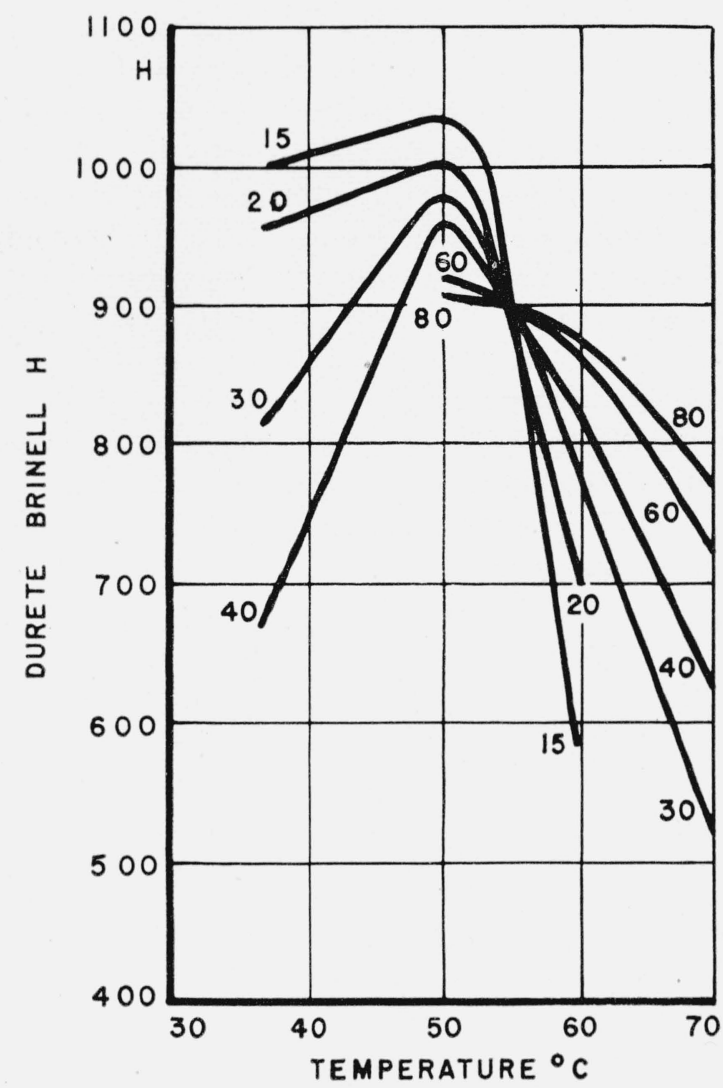

Figure 11. Cymboliste's data [7], showing the effect of temperature of deposition on the hardness of chromium deposits.

Values on the curves are in $\mathrm{amp} / \mathrm{dm}^{2}$.

ing the hardness of the $50^{\circ} \mathrm{C}$ deposits, is above the curves for the deposits plated at other temperatures.

It will be noted from figure $10, \mathrm{~b}$, that the curves of hardness plotted against current density do not show the maxima characteristic of figures 11 and 12 in which hardness is plotted against temperature. The trend of hardness with current density is downward at $50^{\circ} \mathrm{C}$ and upward at more elevated temperatures. It is likely that all the curves would show the downward trend if the observations were extended to very high current densities.

\section{Effect of Composition of Bath}

As compared with temperature and current density, the composition of the plating solution has only a minor effect of the hardness of deposits. Cymboliste found that softer deposits are obtained from solutions high in chromic acid. Our data do

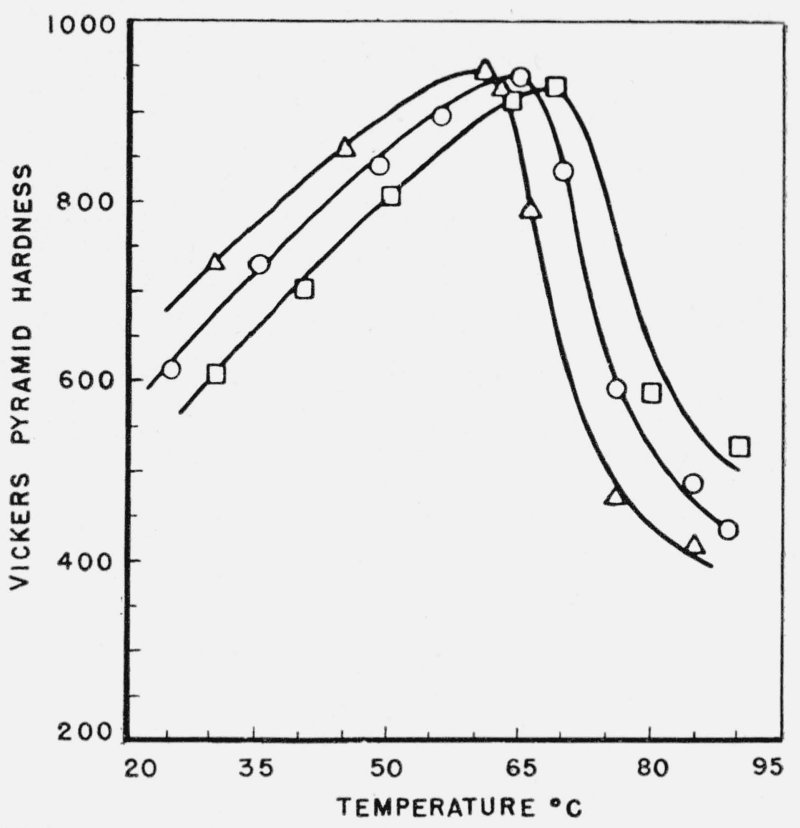

FIGURE 12. Hume-Rothery's data, showing the effect of temperature of deposition on the hardness of chromium deposits.

口, 1,750 amp/ft2 $; \bigcirc, 1,000 \mathrm{amp} / \mathrm{ft}^{2} ; \triangle, 500 \mathrm{amp} / \mathrm{ft}^{2}$.

not indicate any such definite trend. In deposits 8 and 48 (table 6), the deposits from the stronger solution is softer, but a comparison of 29,32 , and 37 , respectively, with 42,43 , and 45 shows that the change is either slight or in the opposite direction. The data on deposits from solutions containing fluorides indicate that these deposits may be harder than those from the sulfate solutions. (Compare deposits 29, 30, 31, and 32 with $53,54,50 \mathrm{a}$, and 55 , respectively).

\section{Effect of Heat Treatment of Chromium}

Chromium softens on annealing at high temperatures. Several investigators have shown that chromium does not begin to soften until the temperature of annealing is carried above $400^{\circ} \mathrm{C}$. The curves in figure 13 show that the hardness of all types of deposits drops to 200 to 250 Knoop after annealing at $1,200^{\circ} \mathrm{C}$ for 1 hour.

\section{Relation Between Hardness and Oxygen Content}

The oxygen content of chromium is one of the most important factors affecting its hardness. The data illustrated in figure 10, c, (for all types of deposits) show a definite trend of hardness with oxygen content, but no very precise relationship, 


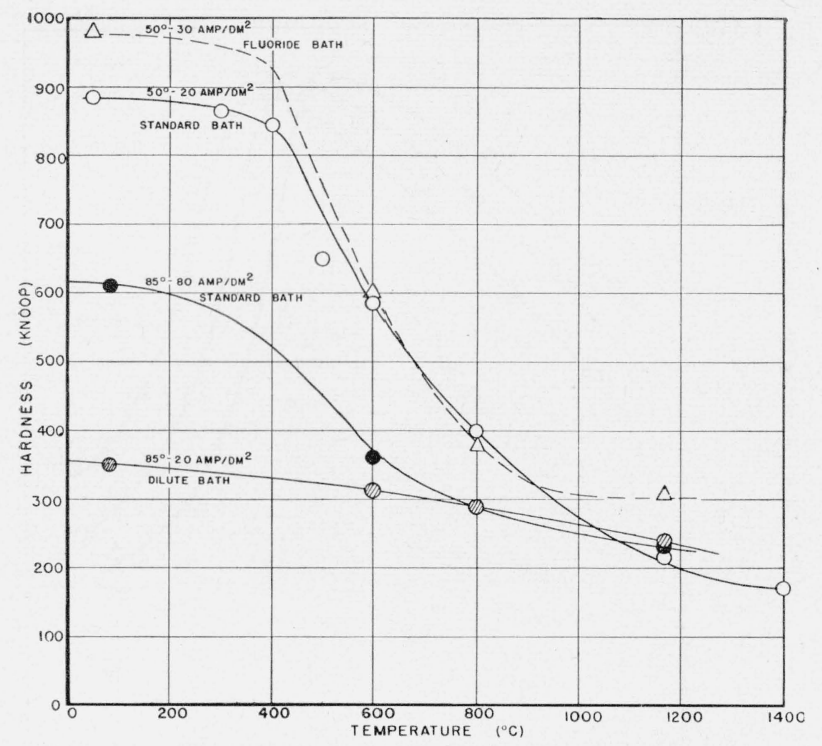

FIGURE 13. Effect of the temperature of annealing on the hardness of chromium deposits.

as other factors besides oxygen content influence the hardness. According to figure 10, c, if the oxygen content of the deposit is above 0.12 percent, the deposits have a hardness ranging from 650 to 1,000 Knoop, and if below 0.12 percent the hardness ranges from 625 down to 325 Knoop. It is to be noted that deposits having about the same oxygen content may vary 200 points or more in hardness.

\section{Cause of the Hardness of Chromium}

The cause of the great hardness of electrodeposited chromium, as compared with cast chromium, has been the subject of considerable speculation and study. At one time it was believed that the hardness of chromium was caused by the presence of hydrogen, but this explanation is no longer tenable for several reasons. The work of Guichard and of Makariewa is perhaps the most conclusive, as they showed that virtually all of the hydrogen can be removed from chromium at a temperature of $400^{\circ} \mathrm{C}$ without the chromium showing any appreciable softening (see fig. 13). Furthermore, no relation was found between the hydrogen content of a chromium deposit and its hardness. An attempt has been made recently to revive the hydrogen theory in another form. It is suggested that during deposition, hydrogen enters the chromium lattice and then escapes, leaving the latter in a state of strain that results in increased hardness. On this basis, the hardness of chromium is to be attributed, not to the hydrogen that is present, but to the hydrogen that has escaped. There is no direct evidence to support this view. Chaudron and Moreau [5] found a relatively slight hardening of iron on cathodically charging it with hydrogen; hence, it is not likely that the strain produced in this way could explain the great hardness of chromium.

Hume-Rothery found a correlation between the hardness of chromium deposits and their degree of crystal orientation. According to him, the brightest deposits are also the hardest and have a preferred crystal orientation, whereas the matte deposits have a random orientation and are softer. However, as he does not show why a preferred orientation should cause a high hardness, it is difficult to explain the hardness of chromium on this basis.

The hardness of chromium is probably the result of three factors: oxide inclusions, small grain size, and internal stress, of which the first two factors are probably the most important. The effect of small grain size and internal stress in increasing the hardness of a metal is well known in general metallurgical practice, but not completely understood. Chromium deposits have been shown by X-ray studies to have a small grain size and a high internal stress. The fact that chromium does not soften appreciably unless annealed at relatively high temperatures indicates that the internal stress is not an important factor in its hardness, because the effects of an internal strain, such as are produced by cold-work, are usually removed by annealing at a relatively low temperature.

The idea that oxide inclusions were responsible for the hardness of electrodeposits was first brought out by MacNaughton [23], but, the manner in which the inclusions produce hardening was not discussed. Nonmetallic inclusions in a metal do not necessarily cause hardening. Desch [8] has made the suggestion, without any further elaboration, that the oxide inclusions in electrodeposits produce hardening in the same manner as the precipitated material does in an age-hardened alloy. In precipitation-hardening, a second phase, consisting of microscopic or even submicroscopic particles, precipitates at the grain boundaries and between the slip planes and causes hardening by 
interfering in some manner with the motion of the slip planes. The precipitated material must be present in sufficient quantity and be of a certain critical size; if too coarse or too fine, an increased hardness does not develop. The phenomena of precipitation-hardening may explain how the oxide content of chromium affects its hardness. If the oxide is in a suitably fine degree of dispersion, as must be the case in the bright deposits, it interferes with the movement of slip planes and produces a high hardness. If the oxide is in a coarse dispersion, as in a burnt deposit, the hardness will be low, even though the oxide content may be high. Hence, a simple precise relation between oxide content and hardness does not exist. As an example, the chromium-iron alloy deposits in table 10 have a very high oxygen content but are relatively soft.

The effects of heat treatment on the hardness of chromium can also be explained on the basis of precipitation-hardening. To the extent that the precipitated material is resistant to agglomeration, age-hardened alloys maintain better their hardness at elevated temperatures and show a higher recrystallization temperature [30]. The oxide dispersion in chromium seems to be stable, as it is only in specimens that have been heated to 1,200 or $1,400^{\circ} \mathrm{C}$ that the oxide can be seen under the microscope. The softness of chromium that has been heated to $1,200^{\circ} \mathrm{C}$ is explained by the agglomeration of the oxide into coarse particles [fig. 5], in which condition they no longer interfere with slip planes.

\section{Machinable Chromium}

The production of a machinable chromium plate may be of interest for special commercial applications. Gardam [12] described a plating solution that would yield a soft chromium of this type having a hardness of about 350 Vickers. It consisted of a standard type chromium plating solution to which iron, aluminum, or chromium had been added, as oxides, to the extent of about $25 \mathrm{~g} /$ liter, for the purpose of improving the cathode current efficiency. The deposit was plated at $85^{\circ} \mathrm{C}$ and $20 \mathrm{amp} / \mathrm{dm} .^{2}$ We have found that an equally soft deposit may be obtained from a simpler plating solution, containing only $\mathrm{CrO}_{3}$, $50 \mathrm{~g} /$ liter; and $\mathrm{SO}_{4}, 0.5 \mathrm{~g}$ /liter (table 1; deposit 42). Furthermore, the cathode current efficiency of this solution, at $85^{\circ} \mathrm{C}$ and $20 \mathrm{amp} / \mathrm{dm}^{2}$ is 15 percent, as compared with 8 percent for Gardam's solution.

A drill rod was plated with chromium from the dilute solution, and the coating was machined with an ordinary high-speed tool. It machined readily, although some dulling of the tool took place, and there was a tendency for the chromium to chip. The same chromium deposit, when annealed at $600^{\circ} \mathrm{C}$ for an hour, machined more easily, but the deposit was cracked as a result of the heat treatment.

\section{Tensile Strength, and Young's Modu- lus of Elasticity}

\section{General}

A knowledge of the mechanical properties of chromium might enable one to decide upon the applicability of chromium for a given engineering use. For example, information on the tensile strength and Young's modulus of elasticity would enable one to calculate the extent to which a plated article could be bent or flexed without cracking the coating. As will be shown, measurement of the mechanical properties of the asdeposited metal does not yield the true physical constants, but values that are dependent on the soundness of the material. Such measurements may give an indication of the relative soundness of different types of deposits.

A survey of the literature showed no previous measurements of the tensile strength or modulus of chromium. The measurement of these properties is difficult, as chromium is very brittle and cannot be gripped readily in a testing machine without cracking. The preparation of test specimens with standard dimensions would involve the plating of very thick deposits, which would require an inordinate period of time. Subsequent machining would be required, which is quite difficult to perform because of the hardness and brittleness of chromium. To expedite the preparation and testing of chromium deposits, test samples were therefore made from tubes, prepared in the manner described above.

\section{Test Specimens and Methods of Measurement}

(a) Tensile Strength

Because of their brittleness, the chromium tubes could not be directly gripped in the jaws of a test. ing machine. Grips were provided by attaching a 


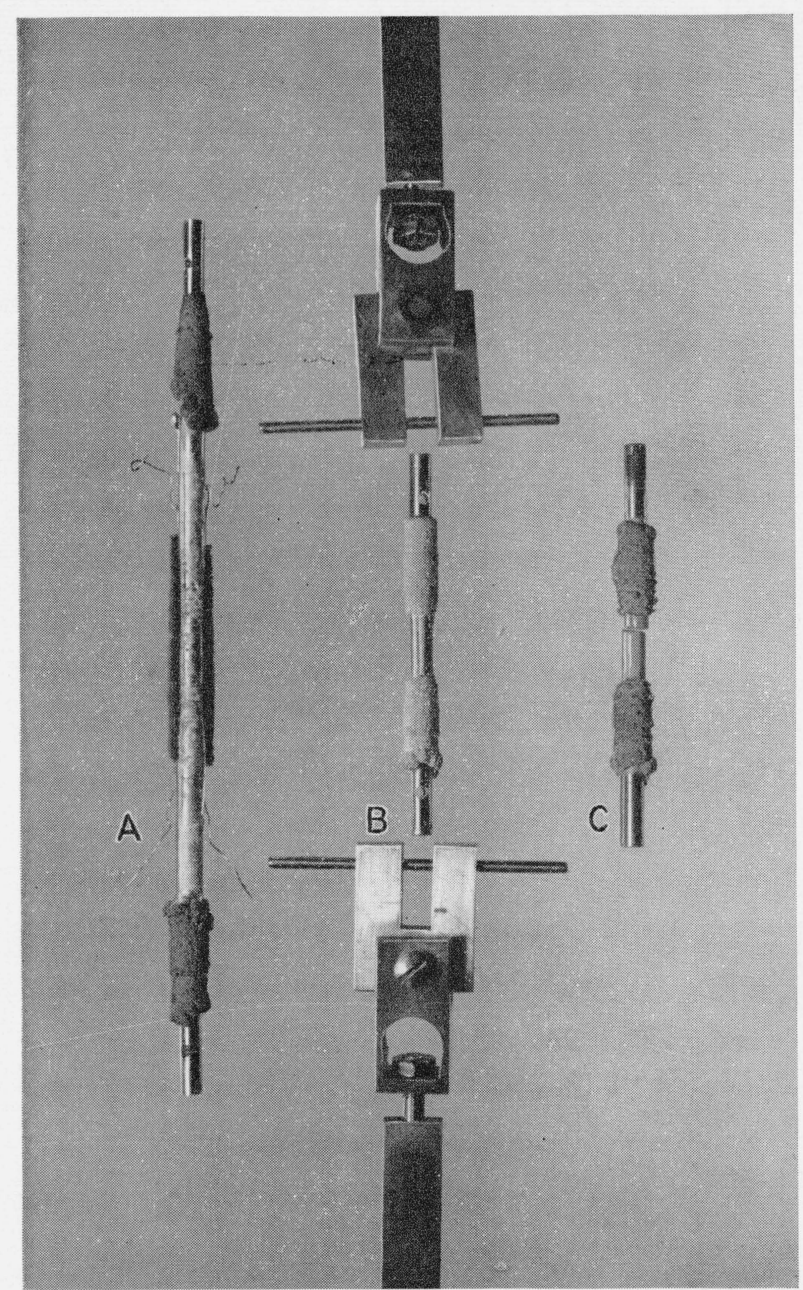

FIGURE 14. A, Chromium tube provided with wire strain gages for determination of Young's modulus of elasticity. $B$, Chromium tube prepared for tensile test, and adapters used for mounting specimen in tensile machine; $C$, specimen broken in tensile test.

steel rod to each end of the tube. This was accomplished by inserting a closely fitting steel rod for a short distance into the end of the chromium tube and then "cold-welding" the rod to the chromium by electro depositing copper over the juncture of the rod and the chromium. The midsection of the test specimen was protected with "stop-off" lacquer during the plating procedure. The plating procedure included use of a nickel strike (Wood's nickel strike: $\mathrm{NiCl}_{2} .6 \mathrm{H}_{2} \mathrm{O}, 240$ $\mathrm{g} /$ liter; $\mathrm{HCl}$, (conc.) $120 \mathrm{ml} /$ liter; current density = 5 $\left.\mathrm{amp} / \mathrm{dm}^{2}\right)$ to produce an adherent nickel coating on chromium, followed by deposition of a thick deposit of copper in an acid bath. Guards were used to produce a tapered copper deposit. A thick nickel deposit could not be used for "coldwelding", because the stress in it broke the ends of the chromium tube.

The specimen was held in an adaptor by means of a pin that passed through a hole near the end of the inserted steel rod. To promote proper alinement of the specimen for uniform distribution of force, the adapter was jointed so as to turn readily in any direction. The adapter was held by the grips of a 600-lb Amsler testing machine. The length of tube subjected to tensile stress was about 1.5 to $2 \mathrm{~cm}$ ( 0.5 to $0.8 \mathrm{in}$.), or about 3 to 4 times the diameter of the tube. A test specimen and the adaptor are shown in figure 14 .

In some preliminary experiments, an attempt was made to determine the mechanical properties of chromium by plating it on a standard steel tensile specimen and observing it while stress was applied. This method was unsatisfactory because the moment at which the chromium cracked could not be ascertained even though the method of detecting cracks by means of copper deposition was used.

\section{(b) Modulus}

In engineering and metallurgical practice, Young's modulus of elasticity is conveniently determined by measuring the extension of a specimen while tension is applied. Some machines have a mechanical device for directly measuring the extension, but usually some form of strain gage that may be mechanical, electrical or optical, is attached to the sample. This procedure could not be applied readily to the tensile test specimen described in the previous section, because the chromium tube was not strong enough to support the weight of most types of strain gages. An optical method [11] that involved the observation of a pair of extensometers with a microscope (in the manner used for measuring creep of metals) was tried, but was not sensitive enough. A few tests were made with an electric strain gage, as described below, but this method was somewhat cumbersome and required the use of highly specialized equipment.

The method that was most satisfactory for a tubular specimen, involved the measurement of the deflection of the midpoint of a tube that was supported horizontally at the two ends and was loaded at the center. The only special equipment required was a low power microscope (a Brinell microscope was used) to measure the de- 


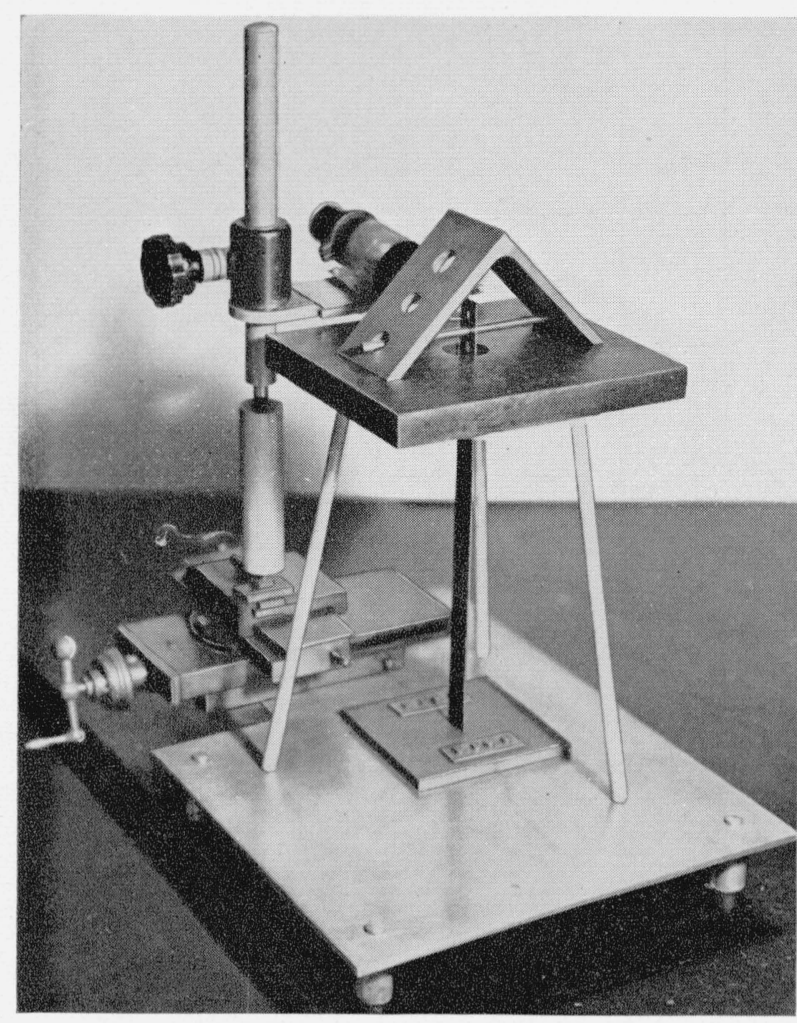

FIGURE 15. Apparatus used for the determination of Young's modulus of elasticity.

flection. The apparatus is shown in figure 15 . The measurements that are required for the determination of the modulus are: Weight of load, deflection of center of tube, length of tube between the supports, and the inner and outer diameters of the tube. A deflection sufficiently large to be read easily with the Brinell microscope could be obtained with a tube $5 \mathrm{~mm}(3 / 16 \mathrm{in}$.) in diameter, having a wall thickness of not over $0.25 \mathrm{~mm}$ (0.01 in.), and a length of $13 \mathrm{~cm}$ (5 in.) between supports. The maximum loads used were about 2,500 g (5 lb.).

Young's modulus, $E$, is defined as the ratio of stress to strain when a material is subjected to tension within its elastic limit:

$$
E=\frac{\text { stress }}{\text { strain }}=
$$

tensile pull per unit area of cross section. extension per unit length

The modulus is calculated from the measurements of the flexure of a tube by the following formula:

$$
E=\frac{4 P L^{3}}{3 \pi \delta\left(d_{1}^{4}-d_{2}^{4}\right)},
$$

where

$E=$ Young's modulus in $\mathrm{lb} / \mathrm{in}^{2}{ }^{2}$,

$\delta=$ deflection in inches,

$P=$ load in pounds,

$L=$ length of specimen in inches,

$d_{1}=$ outer diameter of tube,

$d_{2}=$ inner diameter of tube.

For this formula to hold the strain must be less than 0.2 percent.

The measurement of the inner and outer diameters of the tube have the largest effect on the accuracy of the modulus, as these quantities enter into the equation to the fourth power, and any error is correspondingly magnified. High uniformity of wall thickness was difficult to obtain. For this reason the reported values can be considered accurate to within only about 5 percent, which is sufficient to compare the moduli of different types of chromium deposits. Before being used on chromium deposits, this method was checked by measurements on a steel tube of known modulus.

With the assistance of A. E. McPherson, of the Engineering Mechanics Section of this Bureau, a check was made on a few chromium deposits, using a wire strain gage, which operates on the principle that the electrical resistance of a wire changes when it is subjected to tension. Two wire strain gages were cemented to opposite sides of a chromium tube that had been prepared as for a tensile test. The tube was then subjected to tension in an Amsler machine, and the two gage readings were taken. Observed differences in the two gage readings indicated that the stress was not equal throughout the specimen, probably because of imperfect alinement, but the average of the two readings was a valid measure of the extension of the tube. The first gage tried was a Baldwin wire-gauze, type $\mathrm{A}-7$. The results were erratic, varying by \pm 10 percent from the average, because of the curvature of the gage when wrapped around the tube. A single-wire gage, type A-12-4 was found satisfactory and gave results that agreed within a few percent with those obtained by flexure. A specimen carrying two of these strain gages is shown in figure 14 .

\section{Results of Measurements}

The data (table 7) show that the tensile strength and modulus of chromium, as deposited, vary considerably with the conditions of deposition. 


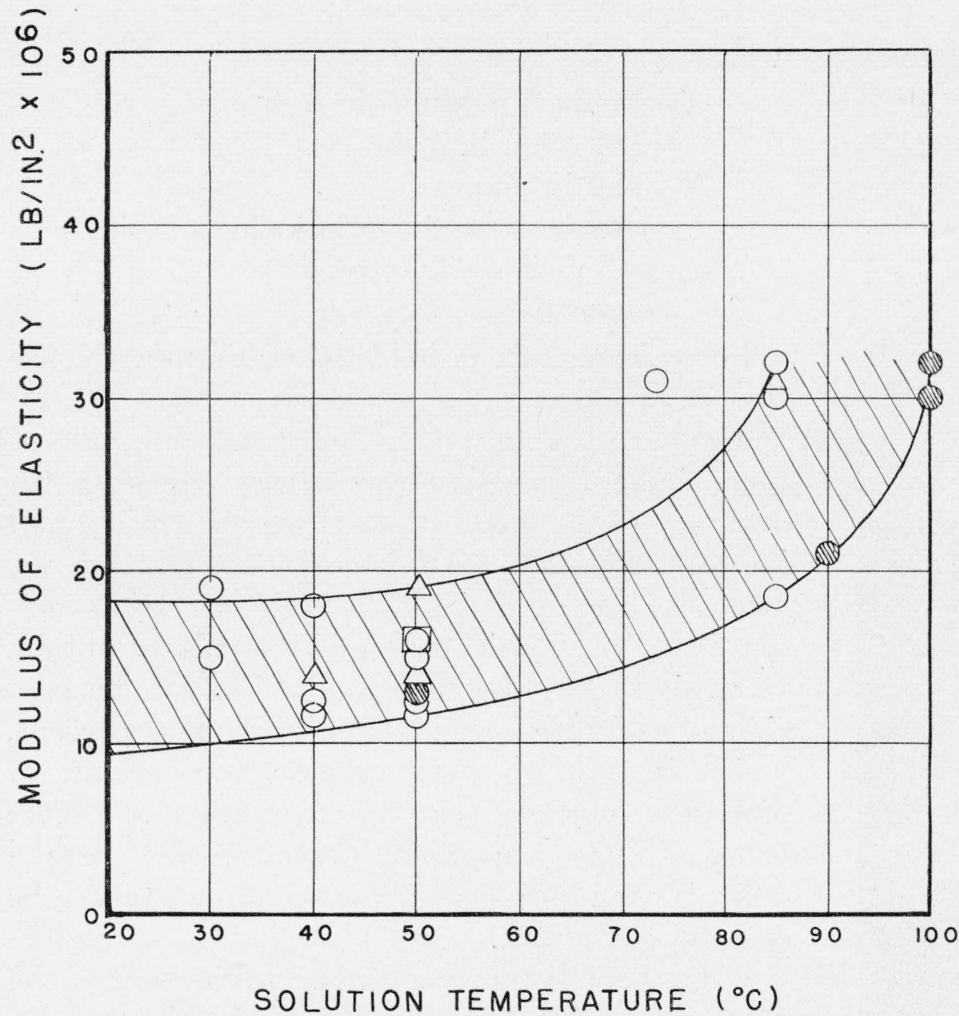

a

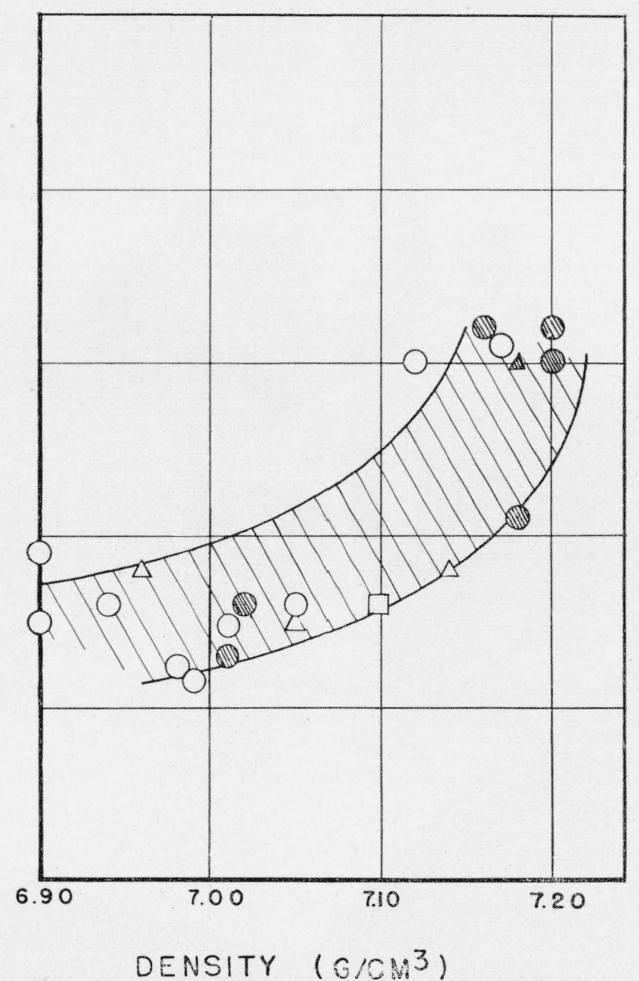

b

FIgURE 16. Modulus of elasticity of electrodeposited chromium.

a, Effect of temperature of deposition on Young's modulus of elasticity of chromium deposits - standard, $\bigcirc$; dilute, modulus and density of chromium deposits.

TABLE 7. Young's modulus and tensile strength of electrodeposited chromium

\begin{tabular}{|c|c|c|c|c|c|c|c|}
\hline \multirow{3}{*}{ 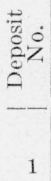 } & \multirow[t]{2}{*}{ Bath } & \multirow{3}{*}{$\begin{array}{c}\begin{array}{c}\text { Tem- } \\
\text { pera- } \\
\text { ture }\end{array} \\
{ }^{\circ} \begin{array}{c}C \\
30\end{array}\end{array}$} & \multirow{3}{*}{$\begin{array}{c}\begin{array}{c}\text { Current } \\
\text { density }\end{array} \\
\text { amp/dm }{ }^{2} \\
5\end{array}$} & \multicolumn{2}{|c|}{ Modulus } & \multicolumn{2}{|c|}{ Tensile strength } \\
\hline & & & & $l b / i n .^{2}$ & $\mathrm{~kg} / \mathrm{mm}^{2}$ & $l b /$ in $^{2}$ & $\mathrm{~kg} / \mathrm{mm}^{2}$ \\
\hline & Standard & & & $19 \times 10^{6}$ & $13 \times 10^{3}$ & $19 \times 10^{3}$ & 1 \\
\hline 2 & $\ldots$..._do & 30 & 10 & 15 & 10 & 16 & 1 \\
\hline 3 & .... do .... & 40 & 15 & 16 & 11 & 17 & 12 \\
\hline 8 & .... do ........ & 50 & 20 & 16 & 11 & 15 & 10 \\
\hline 9 & non & 50 & 30 & 15 & 10 & $\ldots$ & -.. \\
\hline 10 & ..... do & 50 & 40 & 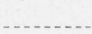 & 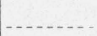 & 17 & 12 \\
\hline 11 & .... do & 50 & 60 & 12 & 8 & $\ldots$ & - \\
\hline 12 & ..... do . & 50 & 80 & 12 & 8 & & . \\
\hline 14 & ..... do & 50 & 280 & $\ldots$ & $\ldots$ & 8 & 6 \\
\hline 26 & do & 75 & 60 & 32 & 22 & & - \\
\hline 30 & ..... do & 85 & 40 & & & 18 & 13 \\
\hline 31 & .... do & 85 & 60 & 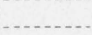 & $\ldots$ & 54 & 38 \\
\hline 32 & _... do . ....... & 85 & 80 & 33 & 23 & 70 & 49 \\
\hline 33 & $\ldots$ do $\ldots$ & 85 & 120 & $\ldots$ & $\ldots$ & 80 & 56 \\
\hline 39 & High $\mathrm{SO}_{4} \ldots$ & 85 & 80 & 31 & 22 & 28 & 20 \\
\hline 40 & Dilute .... & 50 & 10 & 16 & 11 & & \\
\hline 41 & . do & 50 & 20 & 13 & 9 & & - \\
\hline 42 & . & 85 & 20 & 28 & 20 & 46 & 32 \\
\hline
\end{tabular}

TABLE 7. Young's modulus and tensile strength of electrodeposited chromium-Continued

\begin{tabular}{|c|c|c|c|c|c|c|c|}
\hline $\begin{array}{l}\overrightarrow{7} \\
\dot{0} \\
\dot{0}\end{array}$ & Bath & $\begin{array}{l}\text { Tem- } \\
\text { pera- }\end{array}$ & $\begin{array}{l}\text { Current } \\
\text { density }\end{array}$ & \multicolumn{2}{|c|}{ Modulus } & \multicolumn{2}{|c|}{ Tensile strength } \\
\hline 43 & Dilute & ${ }^{\circ} \mathrm{C}$ & $\begin{array}{c}a m p / d m^{2} \\
80\end{array}$ & lb/in. ${ }^{2}$ & $\mathrm{~kg} / \mathrm{mm}^{2}$ & bb/in. ${ }^{2}$ & $\mathrm{~kg} / \mathrm{mm}^{2}$ \\
\hline 44 & ..... do ... & 90 & 80 & 21 & 15 & .... & - \\
\hline 45 & _.... do ... & 100 & 80 & 32 & 22 & $35 \times 10^{3}$ & 25 \\
\hline 46 & ..... do .... & 100 & 100 & 30 & 21 & 27 & 19 \\
\hline 48 & Concentrated.. & 50 & 20 & 16 & 11 & & \\
\hline 50 & Fluoride-1 . . . . . & 50 & 20 & 19 & 13 & & \\
\hline 51 & $\ldots$........... & 50 & 30 & 20 & 14 & 30 & 21 \\
\hline 52 & $\therefore \mathrm{do}_{\ldots} \ldots$ & 50 & 40 & 15 & 10 & $\ldots$ & ... \\
\hline 53 & . . do do . . . & 85 & 20 & 30 & 21 & 31 & 22 \\
\hline 55 & ...... do & 85 & 80 & 20 & 14 & 12 & 8 \\
\hline 57 & Fluoride-3. & 85 & 20 & 31 & 22 & 48 & 34 \\
\hline 58 & Fluoride-4 . . . . & 85 & 20 & 25 & 17 & & \\
\hline 59 & Fluoride-4 & 85 & 80 & 26 & 18 & & \\
\hline 63 & Fluoride-5 ... & 85 & 60 & 21 & 15 & .... & .. \\
\hline
\end{tabular}


TABLE 8. Effect of heat treatment on modulus and tensile strength of electrodeposited chromium

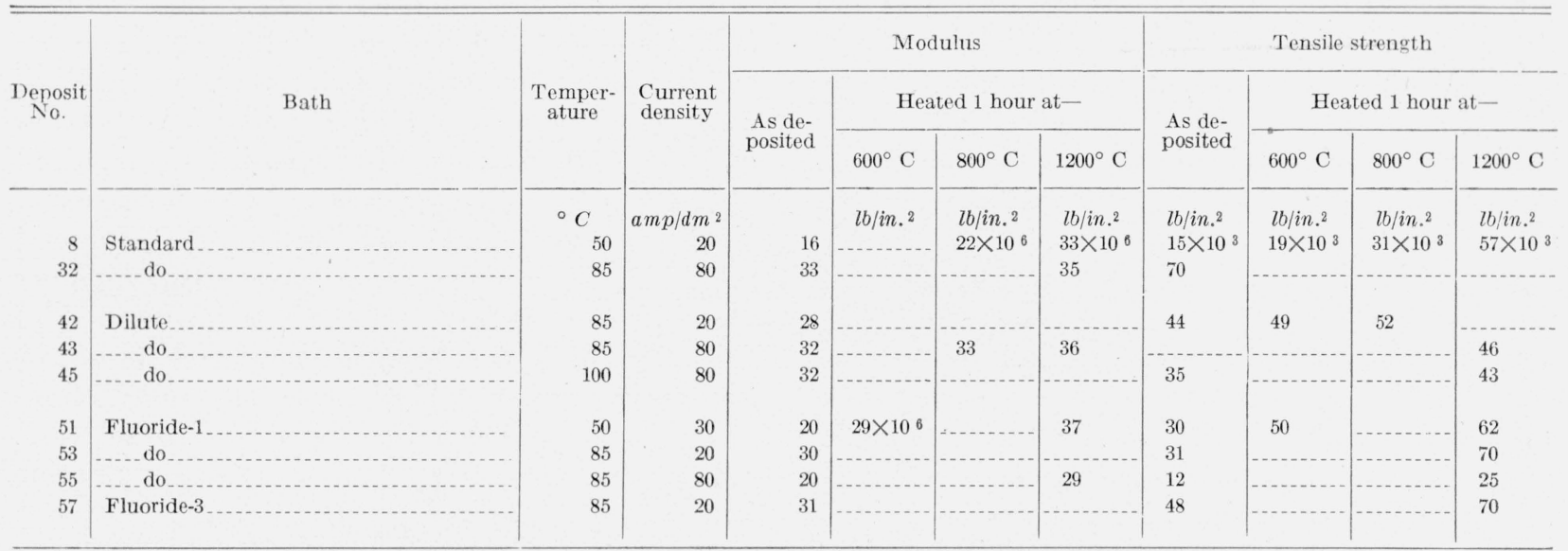

The tensile strength varies from about 15,000 to $80,000 \mathrm{lb} / \mathrm{in}^{2}$ and Young's modulus from $12 \times 10^{6}$ to $33 \times 10^{6} \mathrm{lb} /$ in. $^{2}$ The values are somewhat erratic and do not show any well defined trend, except that the higher values of both were obtained on deposits made at $85^{\circ} \mathrm{C}$ or above (fig. 16).

The data in table 8 show that the modulus and tensile strength of chromium deposits increase on heating. The increase in tensile strength of deposits produced at $50^{\circ} \mathrm{C}$ is about fourfold, but the increase in modulus is not as large.

These results on modulus and tensile strength can best be interpreted on the assumption that they do not represent the true values of these properties, but that they are, "effective" values, which are dependent on, and hence a measure of, the soundness of the deposits. The presence of cracks and inclusions in the deposits, or pits and nodules on the surface, causes low results and the lack of consistency in the measurements. The deposits produced at elevated temperatures are sounder and hence give higher values of mechanical properties. The values of tensile strength are more erratic than those of modulus, which is to be expected, as in stressing a material to the breaking point, a single defect can result in a concentration of stress sufficient to prematurely fracture the deposit. The situation is very similar to that encountered in measuring the properties of a brittle substance, such as glass [29; p. 320]; no reliable measurements of tensile strength can be obtained, because the values are so dependent on the presence of flaws on the surface, although the modulus can be measured readily [29; p. 300].
The increase in tensile strength and modulus on heating is further evidence that the values obtained on chromium as deposited cannot be considered characteristic of the metal. In general when the metals are soft annealed, the tensile strength decreases $[10 ;$ p. 134]; which is opposite to the effect observed here. The increase in Young's modulus was much greater than generally obtained in metals. Higher values of these mechanical properties of chromium on heattreated specimens may be attributed to the increase in soundness of the metal.

In figure $16 \mathrm{~b}$, the modulus is plotted against the density. The reason for selecting the density as the dependent variable is that it can be considered a measure of the soundness of the deposit. A further correlation between the tensile strength of chromium and its soundness will be discussed in connection with the stress in the deposit.

It is believed that the most reliable value of Young's modulus for chromium is about $36 \times 10^{6}$ $\mathrm{lb} / \mathrm{in}^{2}$, as this seems to be the common value approached by the modulus of several different types of deposits that have been annealed at $1,200^{\circ} \mathrm{C}$. The true tensile strength is probably greater than the highest observed value of about $80,000 \mathrm{lb} / \mathrm{in}^{2}$.

\section{Ductility of Chromium}

Although, as mentioned in the introduction, the desire to produce a ductile chromium deposit was the original motive for undertaking this study of properties, ductile chromium was not obtained. For the purposes of this investigation, a metal is considered ductile, if it acquires a permanent 
deformation while being loaded to rupture. In the measurements of modulus of chromium by the method of loading a beam, indications were obtained that chromium lacked ductility. The plot of load against deflection showed no change in slope for specimens loaded to the breaking point. Plastic deformation would have been revealed by $a^{k}$ change in the slope of the curve.

Elongation is commonly measured by the percent increase of a 2-in. gage length on a specimen that has been broken in tension. A measurement of this type was made on a few specimens of chromium prepared in the manner described under tensile strength. The measurements of length were made to 0.001 in. with a traveling microscope. No elongation was found for either bright chromium or a specimen of annealed chromium (at $1,200^{\circ} \mathrm{C}$ ). Therefore, if chromium deforms plastically, the elongation at fracture must be less than one tenth of a percent.

The possibility is not excluded that ductile chromium can be obtained by a metallurgical process that would yield an oxide-free material, inasmuch as normally brittle metals such as titanium and zirconium have been obtained in a ductile condition. Kroll reports [21] that at high temperatures chromium can be hot worked, which is some indication that it is ductile under certain conditions.

As it appears that chromium breaks within the elastic limit, the maximum extension that can be expected when chromium is stressed in tension can be calculated. If the tensile strength of a deposit were $36,000 \mathrm{lb} / \mathrm{in}^{2}$, a modulus of $36 \times 10^{6}$ $\mathrm{lb} / \mathrm{in}^{2}$ would correspond to an extension of 0.1 percent at the breaking point. This demonstrates that a plated metal cannot undergo more than a slight flexing without cracking the deposit.

\section{Stress in Chromium Deposits}

Metals produced by electrodeposition are frequently highly stressed, and there is evidence that this is particularly true of chromium deposits. The stress within a metal deposit is not a physical property, but an understanding of it may help to explain the behavior of some of the deposits.

The formation of cracks in bright chromium plate is usually attributed to rupture of the deposit as a result of a high contractile stress. Some of the specimens plated from the standard bath at elevated temperatures manifested the presence of stress in other ways. For example, deposits plated at $65^{\circ} \mathrm{C}$ were relatively free from cracks; but when the copper base was dissolved away, some of these developed a network of cracks and fell into fragments. Deposits obtained at $85^{\circ} \mathrm{C}$ and $80 \mathrm{amp} / \mathrm{dm}^{2}$ (from the standard solution) appeared quite sound, but developed one or more large, coarse cracks (fig. 6) when the copper was dissolved away. (It may be mentioned at this point that this troublesome cracking of the high temperature deposits can be largely eliminated by using either the dilute plating solution, 40 , or one of the solutions containing fluoride instead of sulfate.)

The stress in chromium deposits was measured by a modification of that well-known method that depends on the bending of a metal strip when only one side is plated. The modification consisted in using a spiral, instead of a flat strip. The measurements were made by S. Senderoff of the Eler:trodeposition Section of this Bureau. The details of the method will be discussed in a forthcoming publication. The results obtained are illustrated by the curves in figure 17, in which stress is plotted against thickness.

Because the stress characteristics of the deposits are not alike, it will be necessary to discuss

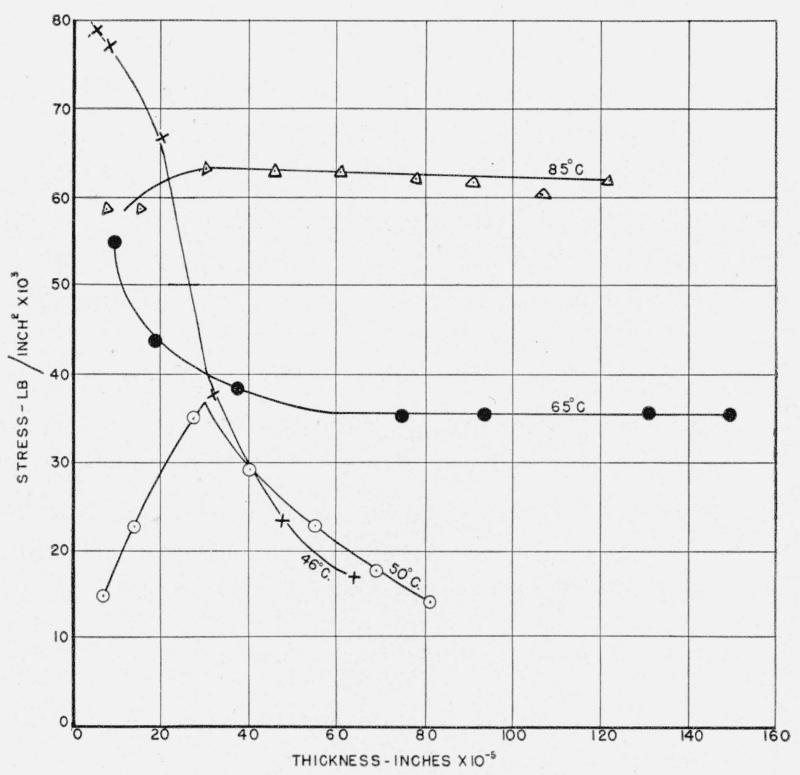

Figure 17. Relation between stress and thickness of chromium deposits.

Plating conditions: $46^{\circ} \mathrm{C} ; 22 \mathrm{amp} / \mathrm{dm}^{2}$; standard plating bath. $50^{\circ} \mathrm{C} ; 20$ amp/dm $\mathrm{dm}^{2}$ standard plating bath. $65^{\circ} \mathrm{C}, 40 \mathrm{mp} / \mathrm{dm}^{2}$; standard plating bath. $85^{\circ} \mathrm{C} ; 20 \mathrm{amp} / \mathrm{dm}^{2}$; dilute plating bath. 
each curve individually. The curves for the $46^{\circ}$ and $50^{\circ} \mathrm{C}$ deposits show that a high stress exists in thin deposits, and that the stress rapidly decreases as the deposit becomes thicker. One explanation of this behavior is that the thin initial deposit is sound, but, at a certain critical thickness, cracking occurs and relieves the stress. This explanation fits in with the observations of Blum, Barrows, and Brenner [4] that bright chromium deposits obtained at $46^{\circ} \mathrm{C}$ and thinner than 0.00002 in., do not contain cracks (immediately after removal from the bath), but that deposits above 0.00005 in. in thickness have cracks. The high stress of 80,000 $\mathrm{lb} / \mathrm{in}^{2}$, attained with the thin deposits, correlates well with the maximum tensile strength that has been measured for chromium, and indicated that bright chromium would have as high a strength as the dull deposits, were it not for the effect of the cracks. As the deposits become thicker, the stress approaches a constant value of about 17,000 $\mathrm{lb} / \mathrm{in} .^{2}$, which is approximately equal to the tensile strength that has been measured for deposits of this type.

The $65^{\circ} \mathrm{C}$ deposit shows a smaller decrease in stress with thickness than the bright deposits. This result fits in with the observation, that fewer cracks are present in such deposits. The presence of a higher residual stress, than in the bright deposits, accounts for the tendency to fall apart when the support afforded by the base metal is removed. The $85^{\circ} \mathrm{C}$ deposit from the dilute bath (deposit 42) was usually sound and didnot show much tendency to erack. This behavior is paralleled by its curve in figure 17, which shows that the stress becomes constant at a high value, indicating no relief through cracking. The stress of $64,000 \mathrm{lb} / \mathrm{in}^{2}{ }^{2}$ would indicate that the tensile $46,000 \mathrm{lb} / \mathrm{in}^{2}{ }^{2}$, measured as described above, is too low. As the stress in the high temperature deposits is close to their tensile strength, it is not surprising that the deposits exhibited cracking occasionally.

Hume-Rothery has measured the stress in chromium deposits, but as the deposition was done at a current density of about $200 \mathrm{amp} / \mathrm{dm}^{2}$, it is difficult to compare his results with ours. He found that the stress varied from about zero for bright deposits to $56,000 \mathrm{lb} / \mathrm{in}^{2}{ }^{2}$ for dull deposits. He attributed the low stress of the bright deposits to their preferred crystal orientation. The maxima and minima in stress that he observed in de- posits obtained at certain temperatures are difficult to explain.

\section{Electrical Resistivity}

The electrical resistivity of chromium is not of much practical importance in itself, but, like the density, it may be an index of the character of the deposits. Once the apparatus is set up, it can be measured quickly. The three physical properties-hardness, density, and electrical resistivity, are valuable in any study of the nature of electrodeposits, because they afford a rapid and sensitive means of following subtle changes that occur in deposits with changes in plating conditions.

Only a few papers in the literature contain data on the resistivity of chromium. Grube and Knabe [19] give a value of 14 microhm-cm at $20^{\circ} \mathrm{C}$ for the resistivity of powdered chromium that had been sintered in hydrogen. They have also determined the resistivities at temperatures up to $1,800^{\circ} \mathrm{C}$, at which temperature the resistivity has increased to 145 microhm-cm. McLennan and Niven [24] reported a value of 44 microhm-cm, for the resistivity of chromium as deposited and 17 microhm-cm for chromium after heating, but they did not give the conditions either of deposition or of heating. Adcock [1] gives 13.1 microhm-cm for chromium annealed in hydrogen. The International Critical Tables give a value of 2.6 microhm-cm, which is incorrectly quoted from Jukov [18]. He actually reported a resistivity of $0.026 \mathrm{ohm}-\mathrm{cm}$ for compressed chromium powder, and his value is not comparable with those for electrolytic chromium.

The resistivity was determined by measuring the potential drop between two knife edges that were placed in contact with a tube of chromium. A current of about 1 ampere was passed through the tube from a separate set of leads. The resistance of the tube was computed from the ratio between the potential drop across the knife edges and the voltage drop across a standard 0.001-ohm resistance. Essentially, the method involves the comparison of the voltage drop across an unknown reistance with that across a known resistance. Because separate connections to the tube were used for the current, their contact resistance did not affect the measurement of the potential difference between the knife 


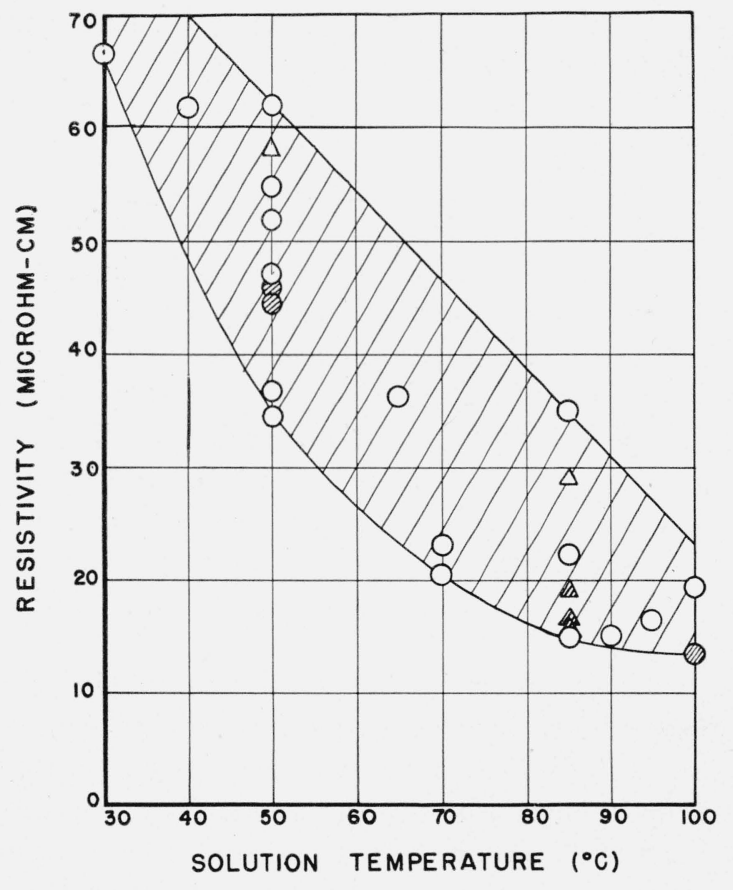

a

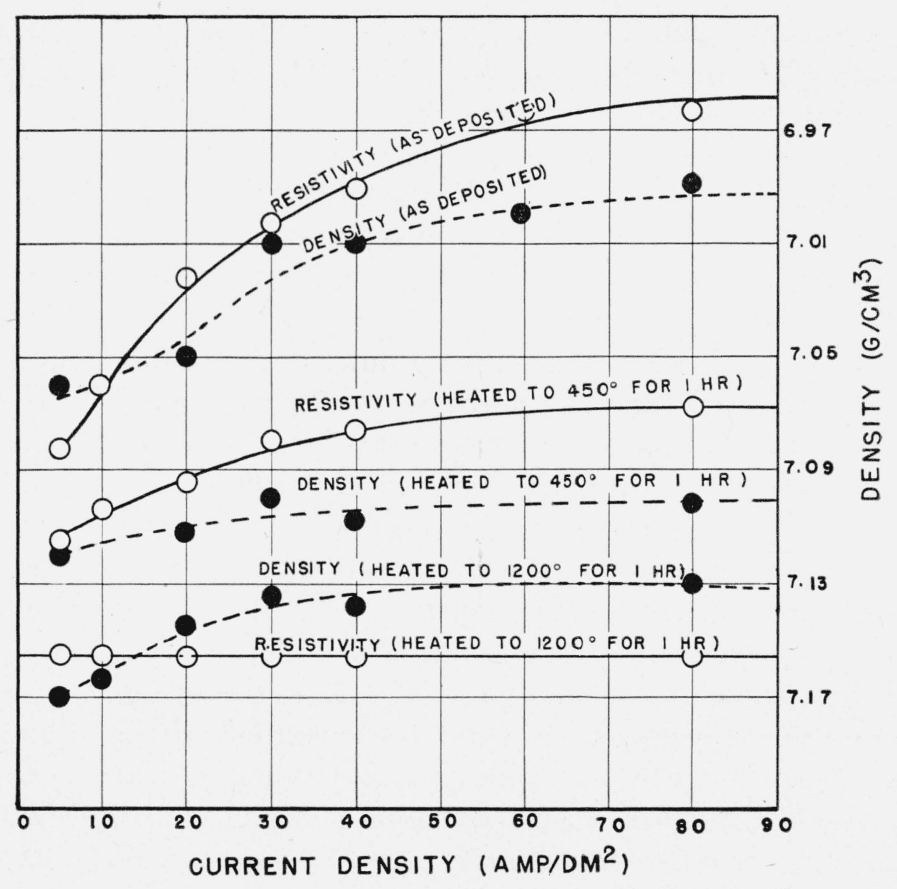

b

FIGURE 18. Relation between electrical resistivity and plating conditions of chromium.

$a$, Effect of temperature of deposition on the electrical resistivity of chromium deposits - standard, $\bigcirc$; dilute, $\ominus$; fluoride, $\triangle$. $\quad b$, Solid lines, effect of current density and the temperature of annealing on the resistivity of chromium. Dotted lines, effect of current density and the temperature of annealing on the density of chromium. Deposits plated at $50^{\circ} \mathrm{C}$ and $20 \mathrm{amp} / \mathrm{dm}^{2}$ in the standard bath.

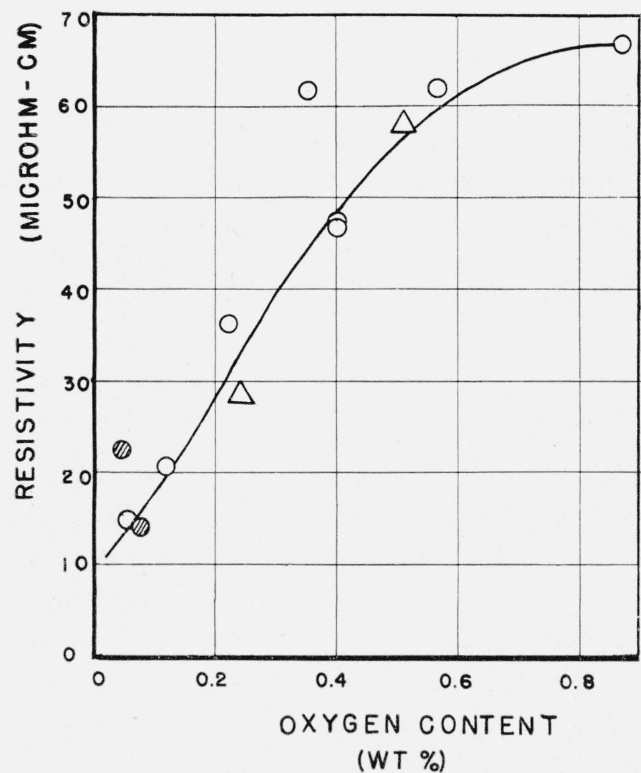

a

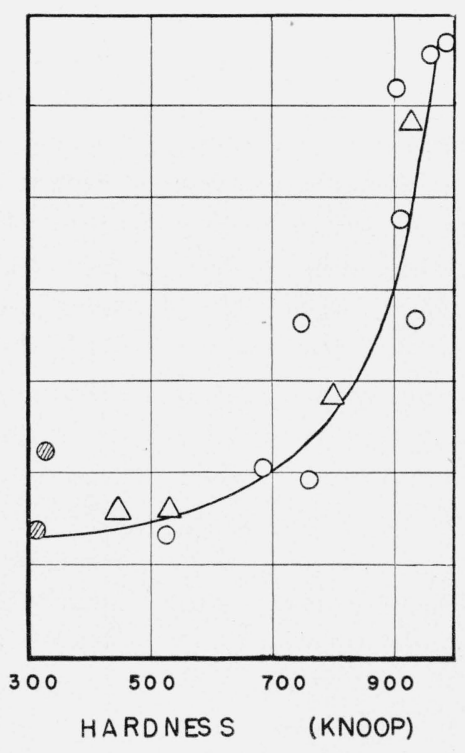

b

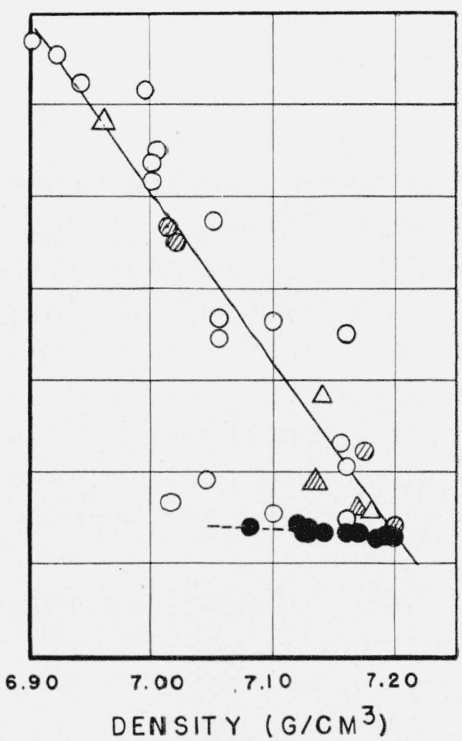

C

FIGURE 19. Relation between electrical resistivity and properties of chromium.

$a$, Relation between electrical resistivity and the oxygen content of chromium deposits; $b$, relation between electrical resistivity and hardness of chromium deposits; $c$, relation between electrical resistivity and density of chromium deposits—standard, $\bigcirc$; dilute, $\ominus$; fluoride, $\triangle$; heat treated, 
edges. A Rubicon potentiometer, sensitive to 1 microvolt, was used along with a sensitive galvanometer. The chromium tubes were about 5 $\mathrm{cm}$ (2 in.) long and the voltage drop across them was of the order of several millivolts. The resistivity setup was designed by R. F. Kotter, of the Electricity and Optics Division of this Bureau.

The data in table 9 show that the resistivity of chromium, as deposited, varies considerably with the conditions of deposition and ranges from 14 to 65 microhm-cm. Figure 18, a, indicates that although a considerable range of resistivities can be obtained at a given temperature (for different plating conditions) the deposits of lowest resistivity are obtained at the elevated temperatures. When plotted against plating variables, such as temperature or current density (fig. 18), or against other properties of the deposits, such as

TABLE 9. Electrical resistivity of electrodeposited chromium

\begin{tabular}{|c|c|c|c|c|c|c|}
\hline \multirow{3}{*}{$\begin{array}{l}\text { De- } \\
\text { posit } \\
\text { No. }\end{array}$} & \multirow{3}{*}{ Bath } & \multirow{3}{*}{$\begin{array}{l}\text { Tem- } \\
\text { pera- } \\
\text { ture }\end{array}$} & \multirow{3}{*}{$\begin{array}{l}\text { Current } \\
\text { density }\end{array}$} & \multicolumn{3}{|c|}{ Restivity } \\
\hline & & & & \multirow{2}{*}{$\begin{array}{l}\text { As de- } \\
\text { posited }\end{array}$} & \multicolumn{2}{|c|}{$\begin{array}{l}\text { Heat treatment, } \\
1 \text { hour, at- }\end{array}$} \\
\hline & & & & & $450^{\circ} \mathrm{C}$ & $1,200^{\circ} \mathrm{C}$ \\
\hline 1 & Standard & ${ }^{\circ} \mathrm{C}$ & $\begin{array}{c}a m p / d m^{2} \\
5\end{array}$ & 66.5 & $\begin{array}{l}\text { Microhm- } \\
\text { cm } \\
34.2\end{array}$ & $\begin{array}{l}\text { Microhm- } \\
\quad \mathrm{cm} \\
\\
14.3\end{array}$ \\
\hline 2 & _. do & 30 & 10 & 66.5 & $\ldots+2$ & $\begin{array}{r}14.0 \\
\ldots \ldots\end{array}$ \\
\hline 3 & _.... do & 40 & 15 & 61.8 & 33.1 & 13.8 \\
\hline 6 & _.... do do & 50 & 5 & 34.5 & 23.8 & 13.8 \\
\hline 7 & ..... do ........... & 50 & 10 & 36.6 & 26.5 & 13.6 \\
\hline 8 & _. . do do......... & 50 & 20 & 47.5 & 28.9 & 13.5 \\
\hline 9 & . . do............ & 50 & 30 & 51.8 & 32.6 & 13.6 \\
\hline 10 & ..... do . . . & 50 & 40 & 54.8 & 33.6 & 13.6 \\
\hline 11 & _. do do . . . . & 50 & 60 & 61.6 & -.... & … \\
\hline 12 & .... do & 50 & 80 & 61.6 & 35.5 & 13.6 \\
\hline 15 & . . . do do ..... & 65 & 40 & 36.2 & 28.4 & 16.1 \\
\hline 26 & .... do_.... & 75 & 60 & 20.5 & 15.9 & 13.2 \\
\hline 27 & _.... do & 75 & 80 & 23.1 & & $\ldots$ \\
\hline 32 & _..._do do ... & 85 & 80 & 14.9 & 13.6 & 13.0 \\
\hline 34 & .... do .... & 85 & 160 & 35 & & $\ldots$ \\
\hline 35 & .... do ..... & 90 & 80 & 15.4 & 13.8 & 13.0 \\
\hline 36 & ..... do do..... & 95 & 80 & 16.5 & 15.6 & 13.5 \\
\hline 37 & ..... do do.......... & 100 & 80 & 19.3 & ...... & 14.7 \\
\hline 40 & Dilute_.......... & 50 & 10 & 44.8 & & \\
\hline 41 & _... do & 50 & 20 & 46.5 & ... & $\ldots$ \\
\hline 42 & _. do do _. & 85 & 20 & 22 & -...... & 13 \\
\hline 45 & _._. do do _......... & 100 & 80 & 13.8 & 13.6 & 12.9 \\
\hline 51 & Fluoride-1 _..... & 50 & 30 & 58.2 & 16.8 & 14.1 \\
\hline 53 & _... do do . _ _ & 85 & 20 & 15.8 & . & ..... \\
\hline 55 & _... do & 85 & 80 & 29 & & 15.0 \\
\hline 59 & Fluoride-4 & 85 & 80 & 19.2 & & \\
\hline 63 & Fluoride-5 ...... & 85 & 60 & 16.0 & & .. \\
\hline
\end{tabular}

hardness (fig. 19, b), density (fig. 19, c), or oxygen content (fig. 19, a), the resistivity shows a more uniform trend than do other properties similarly plotted.

The resistivity of chromium deposits is lowered by annealing (table 9 ). The resistivity of specimens annealed at $1,200^{\circ} \mathrm{C}$ tends to approach a common value of 13 microhm-cm (at $28^{\circ} \mathrm{C}$ ), which may be considered as the resistivity of pure chromium. This resistivity is attained by those specimens which had the lowest oxide content26, 32, 35, 42, and 45. Figure 18, b, shows the effect of different temperatures of annealing on the resistivity of deposits plated at $50^{\circ} \mathrm{C}$.

The high resistivity of chromium, as deposited, is to be attributed more to the oxide content than to any other factor. This is indicated by the trend of resistivity with oxygen content in figure 19, a. The effect of small quantities of impurities in greatly reducing the conductivity of metals is well known. Although the oxide is still present in the chromium after annealing, it is in an agglomerated form (fig. 5), in which condition, apparently it has little effect on the resistivity or on other physical properties.

The soundness of deposits may also be a factor in determining the resistivity. This is shown by the trend of resistivity with density (fig. 19, c), and by the fact that the deposits with the lowest tensile strength [1, 2, 3, 8, 10, and 55] are among those having the highest resistivities. The presence of internal stress in the deposit cannot be responsible for much of the high resistivity, as it has been shown for copper and iron [10; p. 138] that a high stress increases resistivity by only about 2 percent.

\section{Melting Point of Chromium}

The melting point of chromium was not determined in this study. In the literature, values are given ranging from $1,500^{\circ}$ to $1,900^{\circ} \mathrm{C}$. The most reliable measurement is probably that of Grube and Knabe [14], who obtained the value of $1,890^{\circ}$ $\pm 10^{\circ} \mathrm{C}$ for chromium melted in a hydrogen atmosphere. They showed that the presence of 1 percent of chromic oxide would lower the melting point to about $1,770^{\circ} \mathrm{C}$. Apparently the presence of oxide is responsible for the low and nonconcordant melting points reported by other investigators. 


\section{Heat Treatment of Chromium Depos- ited on a Base Metal}

It would be helpful to be able to take advantage of the enhanced properties possessed by chromium that has been annealed at a high temperature. Some experiments were made to determine the effect of heating thick chromium deposits plated on steel, and on steel first plated with nickel,
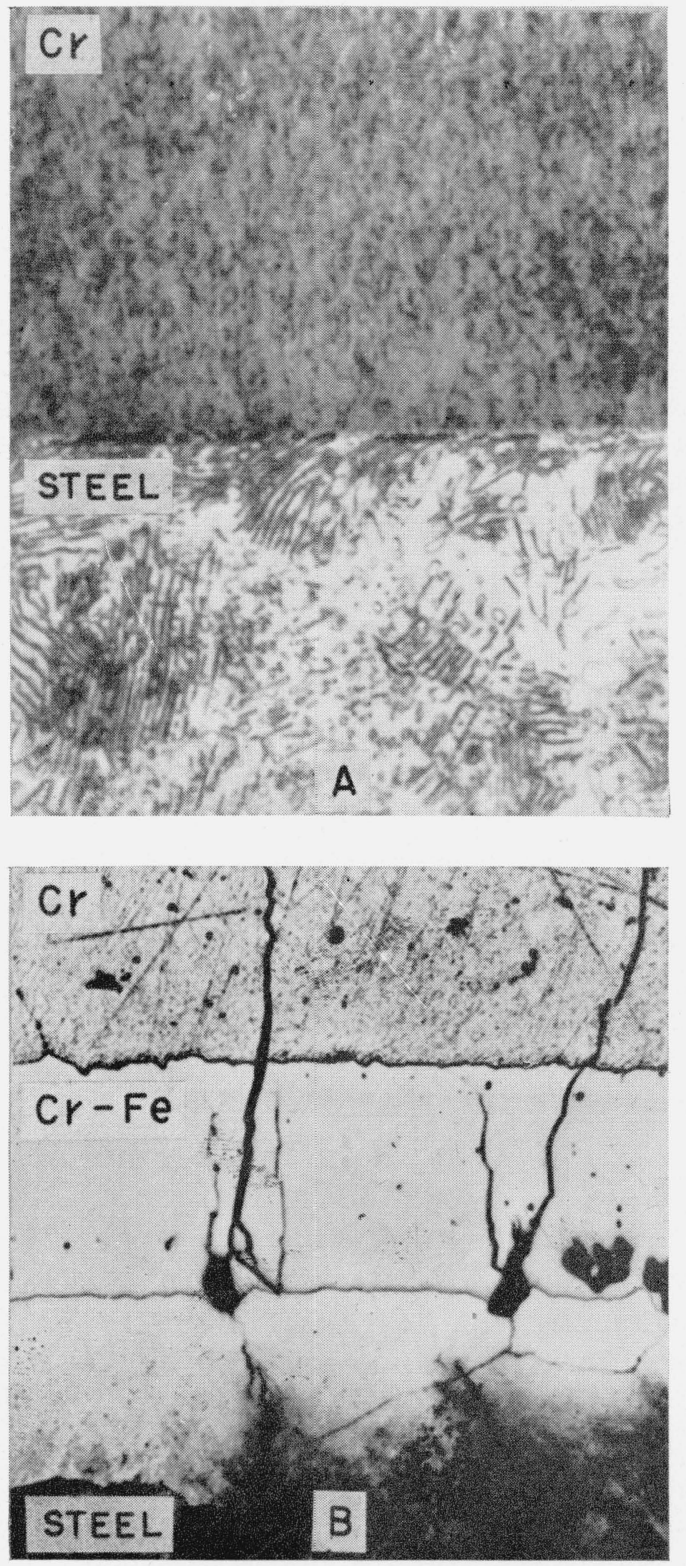

Figure 20. Effect of heat treatment at 1,200 $\mathrm{C}$ of a thick chromium deposit on steel.

Etched with hydrochloric acid. $a$, Before heating $(X 1,000) ; b$, after heatlng $(\times 500)$. cobalt or iron. In all cases, after heating to $1,200^{\circ}$ $\mathrm{C}$ the deposits were badly cracked, and their adhesion to the base metal was so poor that the deposit could be flaked off by bending the specimen. On the other hand, chromium from which the base metal has been stripped remains sound when annealed. The cracking of the chromium is probably a result of the difference between the coefficients of expansion of steel and chromium. The cause of the subsequent poor adhesion seems to be the formation of a brittle alloy layer between the chromium deposit and the base metal (see fig. 20). The chromium that flaked off of the base metal does not contain any of the intermediate metal upon which it was plated, whereas the material remaining on the base metal contains chromium. Hence, the break seems to come between the chromium deposit and the layer of chromium alloy. These difficulties with adhesion and cracking warrant the conclusion that a hightemperature heat-treatment will not improve the properties of chromium in contact with a base metal.

\section{Electrodeposition and Properties of Chromium-Iron Alloys}

Kroll [20] showed that a metallurgical alloy containing mainly chromium and a small amount of iron could be worked while hot. This suggested the possibility of obtaining deposits of chromium alloys that might have more ductility than pure chromium. A study was made of the deposition of alloys of chromium from chromic acid solutions, but as the results of this investigation were mainly negative, they will be described only briefly.

The literature contains a few references to attempts to deposit alloys of chromium from a chromic acid solution. Kasper [19] cites several references to the effect that other metals and chromium do not codeposit. Gardam [12] makes no mention of alloy formation in connection with the introduction of iron in the plating solution used for producing machinable chromium. Watts [34] also was unable to obtain alloys from a chromic acid solution. On the other hand, Skalozubov and Goncharova [32] reported that alloys with nickel and with iron had been obtained from chromic acid solutions.

The following metals were introduced into chromic acid solutions in the attempt to obtain alloys -iron, nickel, cobalt, tungsten, and molyb- 
denum. The metals of the iron group were introduced into the solution mainly in the form of the metal dichromates, but a limited number of experiments were made by adding the metals in the form of other salts. Tungsten and molybdenum were added in the form of complexes with phosphoric, hydrofluoric, or boric acid. No alloys containing more than a few tenths of a percent of the added metal were obtained from any of the solutions except the ones containing iron, and, qualitatively at least, the deposits were usually inferior in physical properties to pure chromium deposits.

The deposits obtained from the solutions recom- mended by Gardam (table 10) are very similar to those obtained from the standard chromium solution [29 to 32], except that they are somewhat softer, although containing more oxide. These deposits contain only several hundredths of a percent of iron. The solution, iron-1 (see table 10) is similar to Gardam's, except that it contains twice as much iron and corresponds essentially to a 2.5-molar solution of iron dichromate $\mathrm{Fe}_{2}\left(\mathrm{Cr}_{2} \mathrm{O}_{7}\right)_{3}$. The deposits contain several tenths of a percent of iron, but are not essentially different from ordinary chromium deposits. The deposits from solutions iron-3 to iron-5 are weak, brittle, and unsound.

TABLE 10. Electrodeposited chromium-iron alloys

\begin{tabular}{|c|c|c|c|c|c|c|c|c|c|c|c|c|c|}
\hline \multirow{2}{*}{ Bath } & \multicolumn{4}{|c|}{ Bath composition } & \multirow{2}{*}{$\begin{array}{l}\text { Tem- } \\
\text { pera- } \\
\text { ture }\end{array}$} & \multirow{2}{*}{$\begin{array}{l}\text { Current } \\
\text { density }\end{array}$} & \multirow{2}{*}{$\begin{array}{l}\text { Cathode } \\
\text { effi- } \\
\text { ciency }\end{array}$} & \multirow{2}{*}{$\begin{array}{c}\text { Hardness, } \\
\text { Vickers }\end{array}$} & \multirow{2}{*}{ Iron } & \multirow{2}{*}{ Oxygen } & \multirow{2}{*}{$\underset{\text { gen }}{\text { Hydro- }}$} & \multirow{2}{*}{$\begin{array}{l}\text { Ratio: } \\
\text { oxygen } \\
\text { to hy- } \\
\text { drogen }\end{array}$} & \multirow{2}{*}{$\mathrm{pH}$} \\
\hline & $\mathrm{CrO}_{3}$ & $\mathrm{Fe}$ & $\mathrm{SO}_{4}$ & $\mathrm{Mg}$ & & & & & & & & & \\
\hline Gardam & $\begin{array}{r}\text { Moles/liter } \\
2.5\end{array}$ & $\begin{array}{c}\text { Moles/liter } \\
0.4\end{array}$ & $\begin{array}{c}\text { Moles/liter } \\
0.025\end{array}$ & Moles/liter & ${ }^{\circ} C_{85}$ & $\begin{array}{c}a m p / d m^{2} \\
20 \text { to } 80\end{array}$ & $\begin{array}{r}\text { Percent } \\
8 \text { to } 12\end{array}$ & 320 to 470 & $\begin{array}{r}\text { Percent } \\
0.1\end{array}$ & $\begin{array}{c}\text { Percent } \\
0.1 \text { to } 0.35\end{array}$ & Percent & & 0.2 \\
\hline Iron-1... & 2.5 & .8 & .025 to .12 & - & 85 & 20 to 80 & 7 to 12 & 360 to 500 & .1 to .5 & .1 to .35 & & & .3 \\
\hline Iron-2... & 2.5 & .8 & .04 & ...... & 45 & 20 & - & 1020 & .0 & .4 & & & .3 \\
\hline Iron-3... & 1.0 & .32 & .17 & 0.16 & 30 & 10 & 47 & 360 & 5.2 & 1.69 & 0.091 & 19 & 1.2 \\
\hline Do... & 1.0 & .32 & .17 & .16 & 50 & 20 & 65 & 340 & 9.0 & 2.85 & .071 & 40 & 1.2 \\
\hline Iron-4... & 1.0 & .64 & .96 & .96 & 25 & 2.5 & 30 & $-\ldots$ & 6.0 & 2.14 & .112 & 19 & 1.6 \\
\hline Do... & 1.0 & .64 & .96 & .96 & 25 & 5 & 43 & 350 & 6.3 & 1.58 & .093 & 17 & 1.6 \\
\hline Iron-5... & 1.0 & .32 & .33 & a. 32 & 30 & 10 & 53 & 350 & 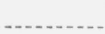 & 1.91 & .067 & 28 & 1.4 \\
\hline
\end{tabular}

a Potassium instead of magnesium.

Although these solutions for plating chromiumiron alloys are not of practical value, they have some points of academic interest, particularly the solutions iron-3 to iron-5. They have an unusually high cathode current efficiency, ranging from 30 to 65 percent, and contain considerably more sulfate than an ordinary chromium plating solution. Solution iron-4 contains almost as much sulfate as chromate, or a ratio of sulfate to chromic acid of about a hundred times greater than is normally present in a chromium plating bath. The high current efficiency of these solutions may be partially a result of the high $\mathrm{pH}$, but this is not the whole story, as solutions with a similar $\mathrm{pH}$, made up by substituting trivalent chromium for the iron, neither plated very satisfactorily, nor yielded high current efficiencies.

The deposits from iron-3 to iron-5 contain a high amount of oxygen, but are not very hard. This shows that the mere presence of oxide inclusions in a deposit is not sufficient to produce hardness, but that the state and dispersion of the basic material is equally important. Because the oxygen to hydrogen ratio of these deposits is 16 or above, the deposits apparently have no free hydrogen (on the basis of our assumption). It is possible, however, that because of the relatively high $\mathrm{pH}$ of the solution, the basic material has separated in the form of a basic iron or chromium dichromate, $\mathrm{Cr}(\mathrm{OH})_{3} \cdot \mathrm{Cr}(\mathrm{OH}) \mathrm{CrO}_{4}$, in which the ratio of oxygen to hydrogen by weight, is 32 . 


\section{Summary}

As the properties of various types of electrodeposited chromium approach a common value after the chromium has been heated to $1,200^{\circ} \mathrm{C}$, the properties of this annealed chromium may be considered to be those of pure chromium. Support for this view is gained from the fact that the density of annealed chromium is $7.20 \mathrm{~g} / \mathrm{cm}^{3}$, the value calculated for pure chromium from X-ray data. The following is a summary of the properties of annealed chromium.

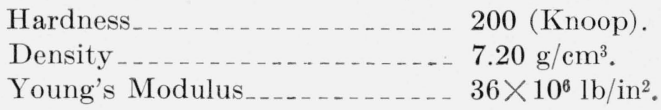

Tensile Strength Resistivity $70,000 \mathrm{lb} / \mathrm{in}^{2}$. 13.0 microhms-cm.

It will be noted that some of the deposits obtained at temperatures between $85^{\circ}$ and $100^{\circ} \mathrm{C}$ have physical properties very close to those of the annealed deposits. The inference is that these deposits are the purest and soundest ones and are most likely to be satisfactory for any purpose other than those requiring high hardness. In table 11, the properties of some of the best hightemperature deposits are compared with the commonly used bright chromium, deposited at $50^{\circ} \mathrm{C}$ and $20 \mathrm{amp} / \mathrm{dm}^{2}$.

TABLE 11. Comparison of properties of low temperature $\left(50^{\circ} \mathrm{C}\right)$, high temperature $\left(85^{\circ}\right.$ to $\left.100^{\circ} \mathrm{C}\right)$, and annealed chromium

\begin{tabular}{|c|c|c|c|c|c|c|c|c|c|c|}
\hline \multirow{2}{*}{$\begin{array}{c}\text { Deposit } \\
\text { No. }\end{array}$} & \multirow{2}{*}{ Bath } & \multicolumn{3}{|c|}{ Plating conditions } & \multirow{2}{*}{ Density } & \multirow{2}{*}{$\begin{array}{c}\text { Hardness } \\
\text { Knoop }\end{array}$} & \multirow{2}{*}{$\begin{array}{l}\text { Tensile } \\
\text { strength }\end{array}$} & \multirow{2}{*}{$\begin{array}{l}\text { Young's } \\
\text { modulus }\end{array}$} & \multirow{2}{*}{ Resistivity } & \multirow{2}{*}{$\begin{array}{l}\text { Oxygen } \\
\text { content }\end{array}$} \\
\hline & & $\begin{array}{l}\text { Tempera- } \\
\text { ture }\end{array}$ & $\begin{array}{l}\text { Current } \\
\text { density }\end{array}$ & $\begin{array}{l}\text { Cathode } \\
\text { efficiency }\end{array}$ & & & & & & \\
\hline 8. & Standard & ${ }^{\circ} C_{50}$ & $\begin{array}{r}a m p / d m^{2} \\
20\end{array}$ & $\begin{array}{r}\text { Percent } \\
15\end{array}$ & $\begin{array}{l}\mathrm{g} / \mathrm{cm}^{3} \\
7.05\end{array}$ & 920 & $\begin{array}{l}7 b / i^{2} \\
15 \times 10^{3}\end{array}$ & $\begin{array}{l}l b / \text { in }^{2} \\
15 \times 10^{6}\end{array}$ & $\begin{array}{r}\text { Microhm-cm } \\
47\end{array}$ & $\begin{array}{l}\text { Percent } \\
0.40\end{array}$ \\
\hline 42. & Dilute...... & 85 & 20 & 15 & 7.18 & 325 & 47 & 30 & 22 & .04 \\
\hline $53 \ldots \ldots$ & (2.2. & 85 & 20 & 15 & 7.18 & 470 & 31 & 30 & 16 & .... \\
\hline 32 & Standard & 85 & 80 & 11 & 7.17 & 550 & 70 & 33 & 15 & .05 \\
\hline \multirow[t]{2}{*}{$45 \ldots \ldots$} & Dilute & 100 & 80 & 8 & 7.20 & 310 & 35 & 32 & 14 & .08 \\
\hline & Annealed, $1,200^{\circ} \mathrm{C} \ldots \ldots \ldots$ & . & & & 7.20 & 200 & 70 & 36 & 13 & -. \\
\hline
\end{tabular}

The authors express their appreciation to W. Blum for his interest and guidance, and acknowledge the assistance of E. F. Osborn, formerly of the Geophysical Laboratory, in the earlier part of this study.

\section{References}

[1] F. Adcock, J. Iron Steel Inst. (London) 124, 99 (1931).

[2] F. Adeock, J. Iron Steel Inst. (London) 115, 369 (1927).

[3] W. Arkharow, J. Tech. Phys. (USSR) 3, 1072 (1936).

[4] W. Blum, W. P. Barrows, and A. Brenner, BS J. Research 7, 697 (1931) RP368.

[5] G. Chaudron and L. Moreau, Korrosion \& Metallschutz 18, 134 (1942),

[6] J. B. Cohen, Trans. Electrochem. Soc. 86, 441 (1944).

[7] M. Cymboliste, Trans. Electrochem. Soc. 73, 353 (1938).

[8] C. H. Desch, Trans. Faraday Soc. [2] 31, 1045 (1935).

[9] G. Dubpernell, Trans. Electrochem. Soc. 80, 589 (1941).

10] C. F. Elam, Distortion of metal crystals, p. 137, (Clarendon Press, Oxford, 1935).
[11] J. A. Fellows, E. Cook, and H. S. Avery, Trans. Am. Inst. Mining Met. Engrs. 150, 358 (1942).

[12] G. E. Gardam, J. Electrodepositors' Tech. Soc. 20, 69 (1945).

[13] H. Gernet, J. Applied Chem. (USSR) 4, 429 (1931).

[14] G. Grube, B. Knabe, Z. Elektrochem. 42, 793 (1936).

[15] P. Hidnert, Phys. Rev. 39, 186 (1932).

[16] Guichard, Clausmann, Billon, and Lanthony, Bul. Soc. Chim. 1, [5] 679 (1934).

[17] M. Jenicek, Ladislaw, Rev. mét. 33, 371 (1936).

[18] I. I. Jukov, J. Russ. Phys. Chem. Soc. 42, 40 (1910).

[19] C. Kasper, J. Research NBS 14, 693 (1935) RP797.

[20] W. Kroll, Z. Metallkunde 28, 317 (1936).

[21] W. Kroll, Z. anorg. Chem. 226, 23 (1936).

[22] R. R. Lloyd, W. T. Rawles, and R. G. Feeney, Trans. Electrochem. Soc. 89, (1946).

[23] D. J. Macnaughtan, G. E. Gardam, R. A. F. Hammond, Trans. Faraday Soc. 29, 729 (1933).

[24] J. C. MeLennan and C. D. Niven, Phil. Mag. [7], 4, 397 (July 1927).

[25] E. Martin, Metals \& Alloys, 1, 831 (1930).

[26] S. P. Markariewa, and N. D. Biriikoff, Z. Elektrochem. 41, 838 (1935). 
[27] S. P. Makariewa, and N. Dirukoff, Z. Elektrochem. 41, 623 (1935).

[28] D. P. Smith, and G. A. Moore, Trans. Electrochem. Soe. 71, 545 (1937).

[29] G. W. Morey, The properties of glass, Am. Chem. Soc. Monograph No. 77 (Reinhold Publishing Corp., New York, N. Y., 1938).

[30] E. R. Parker, Trans. Am. Soc. Metals 28, 797 (1940).

[31] K. Sasaki and S. Sekito, Trans. Electrochem. Soc. 59, 437 (1931).

[32] M. F. Skalozubov, and Goncharova, Izvest. Novocherkass-kogo Ind. Inst. im. S. Ordzhonekidze 6, Ser. Khim. 24 (1940).

[33] H. C. Vacher and L. Jordan, BS J. Research 7, 375 (1931) RP346.
[34] O. P. Watts, Trans. Electrochem. Soc. 84, 350 (1943)

[35] H. B. Weiser, Inorganic Colloid Chemistry, p. 2 (John Wiley \& Sons, Inc., New York, N. Y., 1935).

[36] R. M. Wick, Chromium plating, U. S. Patent 2,392,871 (January 15, 1946).

[37] W. A. Wood, Trans. Faraday Soc. 31, [2] 1248 (1935).

[38] W. A. Wood, Phil. Mag. [7] 23, 984 (1937).

[39] L. Wright, H. Hirst, and J. Riley, Trans. Faraday Soc. [2] 31, 1253 (1935).

[40] W. Hume-Rochery, and M. R. J. Wyllie, Proc. Roy. Soc. (Lonon) [A] 181, 331 (1943). Washington, July 18, 1947.

Washington, July 18, 1947. 